\title{
Markets Reduce Discrimination
}

\author{
Daniel Müller and Fabian Paetzel*
}

February 13, 2021

\begin{abstract}
This paper studies the ability of markets to alleviate taste-based discrimination in a laboratory experiment. We find that markets significantly reduce discrimination relative to individual choice situations with the same payoff structure and the same social group membership of the trading partner. We identify three main mechanisms behind this effect. First, the price of prejudice matters in both situations, but significantly more so in the market. Second, markets reduce identification with one's social group. Third, markets diminish egalitarian preferences. Passive subjects correctly anticipate the main effect. We confirm the main treatment effect in an online experiment with natural groups.
\end{abstract}

Keywords: Discrimination, markets and morals, social identity, minimal groups, natural groups, laboratory experiment.

JEL Classifications: C91, D01, D40, J71.

${ }^{*}$ Daniel Müller (corresponding author): Ludwig Maximilian University of Munich (e-mail: Daniel.Mueller@econ.lmu.de). Fabian Paetzel: Helmut Schmidt University Hamburg (e-mail: fpaetzel@hsu-hh.de). We thank Björn Bartling, Nadja Dwenger, Elisabeth Gsottbauer, Chloé Le Coq, John List, Amma Panin, Rupert Sausgruber, Manuel Schwaninger, Marco Schwarz, Sigrid Suetens, Nora Szech, Stefan Traub, Jean-Robert Tyran, Fabian Waldinger, and Roberto Weber and seminar participants at U Mannheim, LMU Munich, TU Munich and the HSU Hamburg for helpful comments. We are grateful to Ute Losch, Christoph Schütt and Vivien Witte for research assistance. Financial support from the EEEcon at the University of Innsbruck and the German Research Foundation (Research Group FOR 2104 "Need-based justice and distributive procedures") is gratefully acknowledged. 
"Enter into the Royal Stock Exchange of London [...] in which representatives of all nations gathered there for the advantage of mankind. There the Jew, the Mahometan, and the Christian deal with each other as if they were of the same religion, and bestow the name of infidel on bankrupts only [...]." (Voltaire 1764, Philosophical

Dictionary)

\section{Introduction}

Discrimination is one of the most pressing societal and economic problems of our time. While this all too human tendency is now well-documented 1 little is known about how to alleviate this toxic phenomenon. Ever since the famous work of Becker (1957), economists have argued that markets and competition mitigate discrimination (Friedman, 1962, e.g.). The underlying rationale is that markets foster competition, which in turn increases the costs of discrimination. While this hypothesis has become one of the fundamental tenets of economics, it has rarely been subject to empirical scrutiny. Reasons for this gap might be the difficulties entailed in measuring discrimination and in varying the institutional framework, while holding everything else constant. It is for these reasons that we exploit an experimental laboratory study that allows us to control economic incentives, social identity (a person's sense of self) - thus ingroupoutgroup relations - and the institutional framework.

In this paper, we study the ability of markets to reduce discrimination. To do so, we conduct a laboratory experiment that allows for the exogenous variation of the institutional framework and for clean measurement of discrimination. At the same time, the experimental design tightly controls for economic incentives and social group membership. More precisely, we first randomly assign group membership utilizing the "minimal group paradigm" 2 2 We then conduct an experimental posted offer market, in which potential buyers enter in sequential order and choose among the available offers made by the sellers. Buyers not only observe the price of the available (identical) goods, but also the group membership of the sellers. In a next step, we use the payoff structure and the group membership of sellers and buyers from the market to construct an exact control treatment that is stripped off the market context.

Specifically, we take the set of available offers faced by buyers in the market and present exactly the same set, with identical monetary consequences for the subjects, to a different group of participants. Contrary to the market, however, buyers and sellers are referred to in neutral terms - Participant $A$ and Participant $B$ - and there is no mention of any words related to markets such as product, offer or price. Thus, in these control sessions subjects face exactly the

\footnotetext{
${ }^{1}$ See Lane (2016) for a meta-analysis of laboratory studies and Bertrand and Duflo (2017) for a summary of field evidence.

${ }^{2}$ Specifically, groups are induced by purposefully meaningless preferences over painters. Previous research has shown that members of such minimal groups discriminate against the outgroup (Tajfel and Turner, 1979 , Chen and $\mathrm{Li}, 2009$ ).
} 
same payoffs and social identities in the same sequence as do subjects in the market condition in a differently framed choice environment. The comparison of choices in both conditions permits the causal effect of markets on discrimination to be identified whereas discrimination is defined as a positive willingness-to-pay to execute an ingroup trade (as opposed to an outgroup trade).

Our main finding is that markets reduce discrimination in economically significant ways $3^{3}$ We find that costly discriminatory ingroup trades are almost eradicated, down, from $38 \%$ in the neutral control condition, to $7 \%$ in the market. Such a large decrease is remarkable and shows that markets can indeed reduce discrimination. While the main treatment effect in our experiment is due to framing of the decision context, our paper also speaks directly to Becker's famous hypothesis - the idea that competition increases the price of discrimination. This is so because we observe choices with varying prices of discrimination in both conditions. Hence, we are in a position to study the relevance of competition and the effect of a market framing. We find a role for both effects. That is, higher costs decrease discrimination. A market framing increases this effect further. In both conditions, subjects seem to make rational trade-offs since the share of ingroup trades is decreasing in the "price of prejudice" (Becker, 1957). However, the price plays a much more prominent role in the market than in the control condition.

We identify three different mechanisms that drive the main effect. First, as indicated above, markets increase selfishness, that is, market participants focus more strongly on their own payoffs. They are thus less willing to forgo profits in more expensive ingroup trades relative to cheaper outgroup trades. Second, markets diminish identification with one's social group. Our study thus shows how to reduce an individual's sense of self. Third, markets decrease egalitarian preferences: Participants in the neutral control condition are more likely to equalize payoffs between both trading partners.$^{4}$ All three mechanisms are apparent in the (a) descriptive, nonparametric analysis of choice data; (b) parametric estimation of a choice model that combines different motives in a single utility function; and (c) responses to survey items in the postexperimental questionnaire. Finally, we measure beliefs of passive subjects (i.e., sellers in the market and recipients in the control condition) about behavior of decision makers and document that beliefs are in line with the reduced importance of social identity in the market.

We conduct two main robustness checks, in addition to several smaller ones. The first robustness check consists of a laboratory experiment that follows the same structure as the main experiment, but varies the design of the decision screen. Second, we conduct an online experiment that varies several parameters of the laboratory experiment. Most importantly, we

\footnotetext{
${ }^{3}$ We define discrimination as a positive willingness-to-pay to execute an ingroup trade as opposed to an outgroup trade. Our setting prevents price- (e.g. Varian, 1985) and statistical discrimination (e.g. Phelps, 1972), so that only taste-based discrimination can occur. Note that Akerlof (1970) shows that asymmetric information might lead to statistical discrimination and thus provide an argument as to why competitive markets might in fact lead to more discrimination. In this sense, List (2004) provides evidence that statistical discrimination exists in a market with experienced sellers.

${ }^{4}$ While the first and the third channel are related, they are not the same. In principle, both motives can simultaneously be arguments of a utility function and we find evidence for such a claim in the data.
} 
use natural groups (the residents of two large German cities) instead of random groups. In contrast to the laboratory experiment, subjects enter the experiment at different times and are not directly connected with other participants. Such an online experiment likely weakens the tight experimental control that the laboratory allows for, but, in our view, the heterogenous sample of subjects and the variation of different parameters of the experiment also lend credibility and external validity to the main experiment. In both cases, the main effect is confirmed, while somewhat smaller in magnitude, which in turn aids identifying mechanisms driving this effect.

Our paper combines the literature on morality in markets with research on the effect of competition on discrimination and thus contributes to at least two strands of literature. First, it connects to the recent prominent debate in economics on the question whether markets erode social motivations, see Falk and Szech (2013), Bartling, Weber, and Yao (2014), Sutter et al. (2016), and Bartling and Özdemir (2017). A common finding in this literature is that markets erode moral values and lead to more selfishness, which resonates with our results 5 Our paper demonstrates that markets can lead to less immoral behavior as the surge in selfishness results in reduced discrimination. Hence, the erosion of social motivations can be seen as the bright side of markets. We are aware of two other papers that point to the positive side effects of markets. The first one is Bartling, Grieder, and Zehnder (2017), who find that competitive pricing (as opposed to discretionary price setting power) reduces counterproductive punishments. The second paper by Huck, Lünser, and Tyran (2012) finds that competition in a trust game fosters trust.

Second, we contribute to a small literature that aims to test the effect of competition and the "price of prejudice" on discrimination. There are only a handful of studies that try to test Becker's (1957) "market hypothesis", all of which use observational data 6 Using data from Portuguese firms, Cooke, Fernandes, and Ferreira (2019) find that increased competition in some cases increases the female employment share and that firms with a low female employment share, are more likely to exit. They find that even in such a competitive market, workers price-

\footnotetext{
${ }^{5}$ But for evidence to the contrary see for instance Henrich et al. (2010) and Bartling, Fehr, and Özdemir (2020). Moreover, see also Kirchler et al. (2015) for a literature overview that also summarizes the historical and philosophical debate on the nexus of markets and morality. Moreover, Irlenbusch and Saxler (2019) find that a "buyer-seller" framing increases selfishness in individual exchange situations. Li, Dogan, and Haruvy (2011) study an experimental oligopoly market with group identities and show that there are substantial price differentials between ingroup and outgroup trades. Xu, Potters, and Suetens (2020) study the effect of preceding competitive and cooperative interactions on ingroup bias using an allocation task. They provide evidence that competitive interactions reduce pro-sociality in general, irrespective of whether the interaction partner is an in- or outgroup member. List, Neilson, and Price (2016) provide evidence from a field experiment that pricing decisions and deviations from the rational selfish prediction are related to group membership.

${ }^{6}$ While observational studies are clearly useful, they also suffer from problems. First, observational data do in general not allow to cleanly measure the extent of discrimination because observed disparities may be due to many different motives and need not to imply discrimination. Second, using observational data it is difficult to identify the counterfactual, that is, the extent of discrimination under a different institutional framework (e.g. discrimination in the same firm in a market with less competition). Firms that operate in more or less competitive sectors likely differ along many other unobservable dimensions, too. The same holds true for consumers, who likely partially self-select into market or non-market environments or into more or less competitive environments.
} 
discriminate against customers. Moreover, Weber and Zulehner (2014) show that Austrian firms with a small share of female employees display lower survival rates. Pager (2016) finds that firms that display higher rates of discrimination in an audit study, are less likely to still be in business six years later. Li, Lang, and Leong (2017) study whether discrimination exists in the commercial sex market in Singapore. Finally, Hedegaard and Tyran (2018) as well as Atkin, Colson-Sihra, and Shayo (2021) show that discriminatory behavior is responsive to its costs.

Our findings open up potentials for policy interventions such as the introduction of markets and the enhancement of competition, be it through actual competition or through a framing that introduces a market context 7 In general, any intervention that increases the focus on personal monetary gains might be suitable to decrease taste-based discrimination, although obviously the gains need to be weighed against potential social costs of increased selfishness. In contrast to interventions like the "contact hypothesis" (Allport, 1954), a "market intervention" typically does not rely on self-selection into treatment and has the additional advantage that it is cheap to implement: 8

The rest of the paper is organized as follows: Section 2 describes the main experiment. Section 3 presents the results. In Section 4 , we describe the design and the results from the online experiment and several other robustness checks including an additional laboratory experiment. Finally, Section 5 concludes. Furthermore, the Appendix provides further results and additional information about the experiment.

\section{The Experiment}

This section details the experiment. Subsection 2.1 describes the main laboratory experiment and Subsection 2.2 the logistics.

\subsection{Design of the Experiment}

Figure 1 provides an overview of the structure of the experiment. Both stages of the experiment and the two treatments are explained in detail below. Translated instructions and screenshots for both treatments can be found in Appendix A.8.

Stage I. The first part of the experiment induces social group identity and is exactly the same for the two treatments. We thereby rely on the minimal group paradigm developed in social psychology by Tajfel and Turner (1979), which has since become the standard way to create social groups in a controlled laboratory environment. We follow the experimental procedure introduced to economics by Chen and Li (2009). It first asks all 22 subjects in each session

\footnotetext{
${ }^{7}$ Of course, the data from our study do not necessarily give rise to the conclusion that discrimination is fully eradicated in markets. In fact, there is evidence that discrimination may persist even in competitive markets, see List (2004), Doleac and Stein (2013) and Ayres, Banaji, and Jolls (2015).

"The "contact hypothesis" is the major proposal for reducing discrimination. It claims that, under certain conditions, contact to the outgroup decreases prejudice.
} 


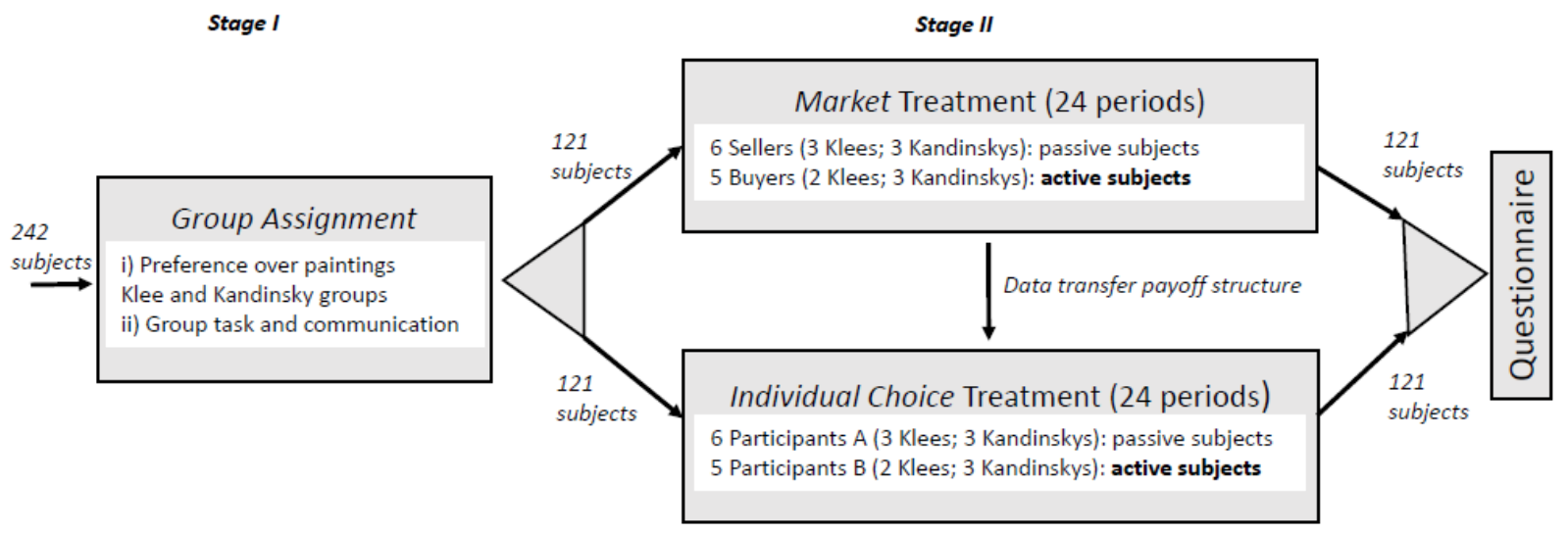

Figure 1: Flow chart for the experiment. Stage I induces social group membership. Subjects were then randomly assigned to the market or the individual choice treatment. The payoff structure of each market was transferred to exactly one session in the individual choice treatment. All subjects participated in the post-experiment questionnaire.

to state their preferences with regard to several pairs of Klee and Kandinsky paintings, five in our case. Depending on their choices (and potentially on drawing a random number to break a tie to ensure equal-sized groups), participants are assigned to either the Klee or the Kandinsky group. Participants are then asked to guess who painted three other paintings, namely either Klee or Kandinsky. During the entire quiz stage, subjects are allowed to communicate with the other members of their own group via a chat program. Participants could earn 1 euro in each of the three guessing tasks if the majority in their group correctly guesses the painter ${ }^{9}$ This evidence thus suggests that the treatment effects observed when using artificial identities are located between those of natural identities.

Stage II. After the first stage, subjects are randomized at the session level either to the market or the individual choice treatment. Each session consists of exactly 22 subjects, who are grouped into two groups of 11 subjects each. Each group is made up of six passive subjects

\footnotetext{
${ }^{9}$ Random assignment to groups has the advantage that both groups are identical in expectation along observed and unobserved background characteristics. Even though minimal groups induced via preferences for paintings are purposefully designed to be meaningless, there is overwhelming evidence that people react to such groups in predictable and economically relevant ways. In particular, membership in such artificial groups leads people to behave more altruistically towards members of the ingroup Chen and Li, 2009, Paetzel and Sausgruber. 2018 Müller 2019), changes the degree of pro-socialness as well as the distribution of equity-efficiency trade-offs (Müller, 2019), affects the decision-making process beyond the direct effect on the utility function (Le Coq, Tremewan, and Wagner, 2015), improves coordination (Chen and Chen, 2011), decreases trust towards the outgroup (Hargreaves Heap and Zizzo, 2009), increases competitiveness (Cornaglia, Drouvelis, and Masella, 2019) and distorts beliefs (Cacault and Grieder, 2019). An alternative approach to creating groups would be to rely on natural identities, such as gender or race, potentially via priming. However, since natural identities are multifaceted, such an approach does not provide the same amount of control as do minimal groups.
} 
(sellers in the market condition or recipients in the individual choice treatment) and five active subjects (buyers in the market condition or dictators in the individual choice treatment). Stage II lasts 24 periods. In this stage, one period is randomly chosen as the payoff relevant period.

One period in the experimental posted-offer market proceeds as follows. Sellers are endowed with one unit of a homogeneous good and simultaneously decide the price $p \in[0,50]$ at which they want to sell it. The buyers then enter the market sequentially in random order. The first buyer can choose from all six offers and decide which of the available offers she wants to buy (if any). If she decides to accept an offer, the second buyer can choose from the remaining five offers and so on. If all buyers in a given period choose an offer, the last buyer has two offers to choose from.

Thus, sequential entry into the market leads to five rounds in each of the 24 periods. The Nash prediction in this game is a price of zero since there are more sellers than buyers 10 The period is finished, after the last buyer makes her choice.

Equations (1) and (2) show the payoff functions of buyers and sellers as a function of the realized price. The payoff function of the seller is 50 tokens plus the price of the offer. Tokens were converted into euros with an exchange rate of 10 tokens equaling 2 euros. The payoff is 50 if no offer is chosen.

$$
\begin{gathered}
P O_{\text {Seller }}= \begin{cases}50+p & \text { if offer with price } \mathrm{p} \text { is accepted } \\
50 & \text { if offer is not accepted }\end{cases} \\
P O_{\text {Buyer }}= \begin{cases}100-p & \text { if offer with price } \mathrm{p} \text { is accepted } \\
50 & \text { if no offer is accepted }\end{cases}
\end{gathered}
$$

The payoff to a buyer is given as 100 minus the price of the accepted offer, or, if no offer was accepted, by 50. A price of 25 would therefore result in payoffs of 75 for both the buyer and the seller. A buyer entering this market not only sees the prices of all available offers, but also the group membership of the sellers ${ }^{11}$

The key to our identification strategy is the fact that the individual choice treatment uses exactly the same payoff structure and the same identities of passive subjects as does the market treatment. To understand exactly how this control works, note that every decision situation in the market can be written as a choice between different allocations of money to the buyer and the potential seller(s). Assume, for example, that a buyer enters the market and observes exactly two offers. The first offer costs $p_{i}$ tokens and is made by an ingroup seller (i.e. either the buyer and the seller are both Klee or both Kandinsky). The second offer is priced at $p_{o}$ tokens and comes from an outgroup seller (i.e. if the buyer is member of the Klee group, the seller is a Kandinsky; if the buyer is a Kandinsky, the seller is a Klee). Such a decision situation boils

\footnotetext{
${ }^{10}$ Empirically however, equilibrium is virtually never reached, see Figure 17 in the Appendix.

${ }^{11}$ While all subjects were members of a group, only the active subjects were informed about the group identity of the passive subjects. This way, we shut down the possibility that subjects form second- and higher-order beliefs about the effect of group identity in this game and thus allows us to tightly control the effect of identity on choices.
} 
down to the choice between one allocation in which the buyer gets $100-p_{i}$ and the ingroup seller gets $50+p_{i}$ and another allocation in which the buyer gets $100-p_{o}$ and the outgroup seller gets $50+p_{o}$. We then create the individual choice condition by transferring this choice situation induced by the market to a market-free context. In the individual choice condition, the active subject is then asked for her preference between the allocation $\left(100-p_{i}, 50+p_{i}\right.$; ingroup $)$ and the allocation $\left(100-p_{o}, 50+p_{o}\right.$; outgroup). If the active subject chooses the ingroup offer when $p_{i}>p_{o}$, we call this discrimination and we call $\left(p_{i}-p_{o}\right)$ the "price of prejudice" or the "price of discrimination". Comparison of the number of discriminatory choices between both treatments constitutes the main analysis of the current paper. We will also analyze the relation of the share of ingroup trades and the price of prejudice.

While the two treatments are economically exactly the same, they differ in their framing. Specifically, the market instructions use the terms sellers who offer products for specific prices and buyers who enter the market to buy those offers. The individual choice treatment, on the other hand, frames the instructions, as five participants $B$ choosing one allocation among a list of allocations, whereas every allocation would induce a distribution of points between the participant $B$ and a participant $A$, keeping everything else constant. That is, the individual choice situation boils down to a dictator game-like situation in which an active subject makes a choice between different allocations of money, while knowing the group identity of each possible recipient.

The same reasoning applies to situations with more than two offers. In this case, the active subject in the corresponding individual choice situation has the choice between more than two allocations ${ }^{12}$ Each decision-maker in the individual choice treatment thereby follows the exact sequence of choices encountered by a specific buyer in the market treatment. That is, for each buyer in the market treatment, there is exactly one corresponding active decision-maker in the individual choice treatment who faces a sequence of 24 identical (in monetary terms and in terms of identity) neutrally framed allocation choices ${ }^{13}$

Passive subjects received feedback on resulting payoffs, but not on identities of active subjects. While active subjects made their choices, we elicited passive subjects' (un-incentivized) beliefs about the behavior of decision-makers. Specifically, we asked passive subjects the following question in both treatments: What percentage of the buyers [participants B] do you think care about the social identity of the sellers [participants B]?

\footnotetext{
${ }^{12}$ Section A.7 in the Appendix shows screenshots and one detailed example of how the offer list from the market treatment is converted to the individual choice treatment.

13 The design of the experiment made it necessary to first run the market game and then transfer the data generated in the market to the individual choice treatment. Every group in every market is thereby matched to exactly one other group in the individual choice treatment. Both groups run through exactly the same payoff structure.
} 


\subsection{Procedural Details}

The experiment was conducted in Spring 2019 at the WISO Experimental Lab of the University of Hamburg, Germany. Participants were recruited via the online tool hroot (Bock, Baetge, and Nicklisch, 2014). The experiment was programmed using z-tree (Fischbacher, 2007). A session lasted approximately 80 minutes. Average payments were around 2 euros in Stage I - the group identification part - and around 15 euros in Stage II - the market and the individual choice treatment. As mentioned before, one round was randomly selected to be paid out.

In total, we conducted 12 sessions, six sessions in the market treatment and six sessions in the individual choice treatment. As a result of a server malfunction the data for Group 1 of Session 5 were not recorded and thus do not form part of the experiment. Not counting these excluded data, 242 participants (110 active and 132 passive) took part in the experiment (none of them participated in more than one session). Consequently, we observe choices of 55 buyers and 55 dictators which yields 2, 640 observations in total (110 active subjects times 24 periods), or 1,320 observations in each treatment 14

\begin{tabular}{lcccccc|c|c}
\hline \hline & \multicolumn{2}{c}{ Market } & & \multicolumn{2}{c|}{ Individual Choice } & & Available in \\
\cline { 2 - 3 } & Choice & No Choice & & Choice & No Choice & Sum & both treatments \\
\hline Best-Out > Best-In & 358 & 8 & & 361 & 5 & 732 & 354 \\
Best-Out = Best-In & 381 & 1 & & 375 & 7 & 764 & 374 \\
Best-Out < Best-In & 411 & 6 & & 411 & 6 & 834 & 405 \\
Only-Out or Only-In & 152 & 3 & & 151 & 4 & 310 & 155 \\
\hline Sum & 1,302 & 18 & & 1,298 & 22 & 2,640 & 1,288 \\
\hline \hline
\end{tabular}

Table 1: Number of observations in each cell. "Best-In" ("Best-Out") denotes the value of the best available ingroup (outgroup) option. "No Choice" indicates cases where the subject did not choose an offer. "Only-Out" or "Only-In" indicate situations in which either only ingroup or only outgroup offers were available to the active subject.

Table 1 summarizes the number of observations in each cell. "Best-Out > Best-In" thereby refers to a situation in which an offer from the outgroup would lead to a higher payoff for the buyer than any offer from an ingroup member. "Best-Out $<$ Best-In" denotes a situation in which an ingroup offer delivers a higher payoff than any available outgroup offer. Moreover,

\footnotetext{
${ }^{14}$ We note that in 155 of the 1,320 choice situations there was either no ingroup or no outgroup offer available. Obviously, these situations cannot be used to measure discrimination and are thus not used in the main part of the analysis. Moreover, we find that in 18 (22) of the 1,320 decisions made in the market (individual choice treatment), a buyer (dictator) opted to not take up an offer (choose an allocation). We exclude these observations in what follows. The possibility to opt out is one essential feature of markets outside the laboratory and therefore also possible in our experiment (see also Bartling, Weber, and Yao, 2014).
} 
"Best-Out = Best-In" implies that the best available ingroup offer denotes a situation in which both options yield the same payoff. Comparison of the choices between the market and the individual choice treatment when the best outgroup offer is larger than the best ingroup offer ("Best-Out > Best-In") is the main focus of this paper. In this cell, we observe 354 choices in the market treatment and 354 exact control observations in the individual choice treatment. Ultimately, $3 \%$ of the offers chosen in the market and $13 \%$ of the offers in the individual choice treatment exhibit a payoff lower than the best ingroup and the best outgroup option. As we show in Section 3.3, these choices can mostly be rationalized by preferences for equality.

\section{Results}

Section 3 is divided into five subsections. In Subsection 3.1, we investigate whether markets are able to reduce discrimination. In Subsection 3.2 , we examine the relevance of the price of discrimination for choices. Subsection 3.3 measures the frequency of four different (non-mutually exclusive) behavioral motives and Subsection 3.4 analyzes data from the exit survey. Finally, in Subsection 3.5, we examine the beliefs of passive subjects concerning the importance of social identity for choices made by active subjects.

\subsection{Do Markets Reduce Discrimination?}

First, we aim to answer our main research question: Do markets reduce discrimination? Figure 2 shows that the answer to this question is clearly yes. The bars display the share of ingroup trades in the market and in the individual choice condition for decisions in which the best ingroup option is more expensive than the best outgroup option. It turns out that the share of ingroup trades is $38.4 \%$ in the individual choice control condition but a staggering $7.3 \%$ in the market. A Wilcoxon rank sum test clearly detects statistically significant differences with a p-value below 0.01 . This difference of more than 30 percentage points implies that the market reduces costly discrimination in our experiment more than fivefold as compared to the individual choice treatment. It is noteworthy that the share of ingroup trades is below $50 \%$ in both treatments (which would result from random behavior) and thus indicates that incentives matter in both conditions 15

Another way to interpret the effect of markets on discrimination in our experiment is by calculating an implicit (minimal) willingness-to-pay to discriminate for each treatment 16 Subjects in the market condition pick in $26(=7.3 \% \times 354)$ cases the ingroup offer when the outgroup offer in fact delivers a higher payoff, thus forfeiting 2.19 tokens on average. Hence, 55 buyers

\footnotetext{
${ }^{15}$ Figure 11 in the Appendix shows the share of ingroup trades when the best ingroup offer is larger and for situations in which the best ingroup and best outgroup offer yield the same payoff. Figures 15 and 16 in the Appendix plot the share of ingroup trades against the different periods of the experiment.

${ }^{16}$ This calculation provides a lower bound of the true willingness-to-pay because it is possible that the decisionmaker would have been willing to pick an even more unfavorable ingroup offer, if available.
} 


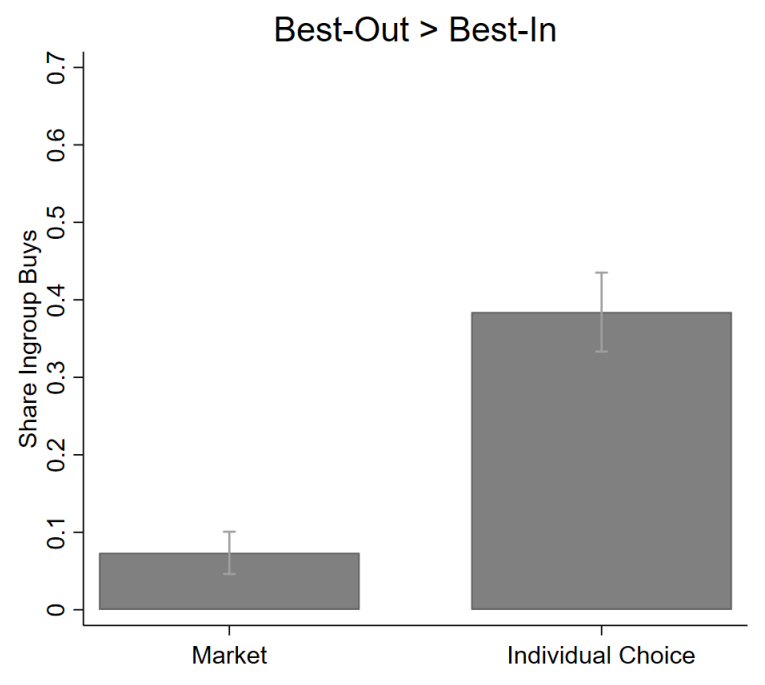

Figure 2: Share of ingroup buys in situations in which the best outgroup option is cheaper than the best ingroup option. $N=354$ in each treatment. The means are $7.3 \%$ in the market and $38.4 \%$ in the individual choice condition. Bars around the means indicate $95 \%$ confidence intervals.

in the market forgo on average $\frac{26 \times 2.2}{55}=1.04$ tokens in the course of the experiment in order to benefit the ingroup. Subjects in the individual choice condition, on the other hand, pick 136 times the ingroup offer when the outgroup offer is higher. They forgo 2.70 tokens on average, which amounts to 6.69 tokens lost during the experiment for each dictator - a number which is more than six times higher than the same number in the market.

These conclusions are corroborated and extended in Table 2 in which we present results from linear regressions. In all these regressions a dummy that indicates an ingroup trade serves as dependent variable. Columns (1) and (2) consider only data from situations in which the best ingroup offer delivers a smaller payoff than the best outgroup offer; columns (3) and (4) consider the opposite situation; and, finally, columns (5) and (6) use all available data.

The coefficient on $I C$, a dummy for the individual choice treatment, is positive in the first two columns and negative in columns (3) and (4), indicating more ingroup trades when "Best-In $<$ Best-Out", but fewer ingroup trades when "Best-In > Best-Out" in the individual choice condition than in the market. Using all available data, this coefficient is negative, around 17 percentage points. The variable price denotes the payoff of the best ingroup option minus the payoff of the best outgroup option, i.e. the (negative) price of prejudice. The coefficient is positive throughout which indicates that the frequency of ingroup trades increases with the price of prejudice. Price is not significant in column (2). Instead, in this column the coefficient on the interaction between $I C$ and price is positive and significant. This finding indicates that the slope of price is steeper in the individual choice condition than in the market. The last two columns use the whole sample and include dummies for "Best-In $<$ Best-Out" and "Best-In $>$ 


\begin{tabular}{|c|c|c|c|c|c|c|}
\hline \multirow[t]{2}{*}{ Ingroup Trade } & \multicolumn{2}{|c|}{ Best-Out > Best-In } & \multicolumn{2}{|c|}{ Best-Out $<$ Best-In } & \multicolumn{2}{|c|}{ Full Sample } \\
\hline & (1) & (2) & (3) & (4) & (5) & (6) \\
\hline $\begin{array}{l}\text { Individual Choice } \\
\text { (IC) }\end{array}$ & $\begin{array}{c}0.309^{* * *} \\
(0.06)\end{array}$ & $\begin{array}{c}0.362^{* * *} \\
(0.07)\end{array}$ & $\begin{array}{c}-0.104^{* *} \\
(0.04)\end{array}$ & $\begin{array}{c}-0.117^{* *} \\
(0.05)\end{array}$ & $\begin{array}{c}-0.167^{* * *} \\
(0.05)\end{array}$ & $\begin{array}{c}-0.167^{* * *} \\
(0.05)\end{array}$ \\
\hline Price & $\begin{array}{c}0.012^{* * *} \\
(0.00)\end{array}$ & $\begin{array}{l}0.003 \\
(0.00)\end{array}$ & $\begin{array}{c}0.008^{* * *} \\
(0.00)\end{array}$ & $\begin{array}{c}0.006^{* *} \\
(0.00)\end{array}$ & $\begin{array}{c}0.011^{* * *} \\
(0.00)\end{array}$ & $\begin{array}{c}0.005^{* *} \\
(0.00)\end{array}$ \\
\hline $\mathrm{IC} \times$ Price & & $\begin{array}{c}0.018^{* *} \\
(0.01)\end{array}$ & & $\begin{array}{l}0.005 \\
(0.01)\end{array}$ & & $\begin{array}{c}0.012^{* * *} \\
(0.00)\end{array}$ \\
\hline Best-In larger & & & & & $\begin{array}{l}0.039 \\
(0.03)\end{array}$ & $\begin{array}{l}0.055 \\
(0.03)\end{array}$ \\
\hline IC $\times$ Best-In larger & & & & & $\begin{array}{l}0.063 \\
(0.05)\end{array}$ & $\begin{array}{l}0.030 \\
(0.06)\end{array}$ \\
\hline Best-In smaller & & & & & $\begin{array}{c}-0.773^{* * *} \\
(0.04)\end{array}$ & $\begin{array}{c}-0.791^{* * *} \\
(0.04)\end{array}$ \\
\hline IC $\times$ Best-In smaller & & & & & $\begin{array}{c}0.477^{* * *} \\
(0.07)\end{array}$ & $\begin{array}{c}0.512^{* * *} \\
(0.07)\end{array}$ \\
\hline Period & $\begin{array}{l}0.003 \\
(0.00)\end{array}$ & $\begin{array}{l}0.003 \\
(0.00)\end{array}$ & $\begin{array}{l}0.001 \\
(0.00)\end{array}$ & $\begin{array}{l}0.001 \\
(0.00)\end{array}$ & $\begin{array}{l}0.001 \\
(0.00)\end{array}$ & $\begin{array}{l}0.001 \\
(0.00)\end{array}$ \\
\hline Constant & $\begin{array}{l}0.071^{*} \\
(0.04)\end{array}$ & $\begin{array}{l}0.043 \\
(0.04)\end{array}$ & $\begin{array}{c}0.918^{* * *} \\
(0.03)\end{array}$ & $\begin{array}{c}0.924^{* * *} \\
(0.03)\end{array}$ & $\begin{array}{c}0.875^{* * *} \\
(0.03)\end{array}$ & $\begin{array}{c}0.875^{* * *} \\
(0.03)\end{array}$ \\
\hline $\begin{array}{l}\text { Observations } \\
R^{2}\end{array}$ & $\begin{array}{c}719 \\
0.153\end{array}$ & $\begin{array}{c}719 \\
0.160\end{array}$ & $\begin{array}{c}822 \\
0.036\end{array}$ & $\begin{array}{c}822 \\
0.037\end{array}$ & $\begin{array}{l}2297 \\
0.425\end{array}$ & $\begin{array}{l}2297 \\
0.426\end{array}$ \\
\hline
\end{tabular}

Table 2: OLS Regressions with a dummy indicating ingroup trades as dependent variable. Standard errors, clustered at the subject level, in brackets below. ${ }^{*}, * *, * * *$ indicate significance at the $10 \%, 5 \%$ and $1 \%$ level, respectively. Price denotes the payoff difference between the best ingroup and the best outgroup option; $I C$ is a dummy for the individual choice condition; Period denotes the period of the experiment (from 1 to 24); Best-In larger is a dummy indicating situations in which the best ingroup offer is larger than the best outgroup offer; and Best-In smaller denotes the reverse situation. The reference group in Columns (5) and (6) are situations in which in- and outgroup offers deliver the same payoffs.

Best-Out" ("Best-In equal to Best-Out" then serves as the reference group) and interactions of those dummies with the individual choice treatment dummy. The results show that, on average, there are less ingroup trades in the individual choice condition (the coefficient in $I C$ is negative). 
The frequency of ingroup trades drops sharply when ingroup trades are costly (the coefficient on "best-in smaller" is negative) but less so in the individual choice condition (the coefficient on "IC $\times$ best-in smaller" is positive and around 50 percentage points). Again, there is a positive relation between the price of discrimination and the frequency of ingroup trades. This slope is steeper in the individual choice condition ( $\mathrm{IC} \times$ price is positive in column 6 ). Finally, there is no evidence for period effects. All in all, the regression results confirm the visualization of the data in Figure 3 .

\subsection{Price of Prejudice}

Next, we analyze how the frequency of ingroup trades depends on the (negative) price of prejudice (i.e. the payoff of the best ingroup option minus the payoff of the best outgroup option). Figure 3 plots the price of discrimination against the share of ingroup trades. First of all, the figure provides evidence that participants in both treatments seem to react to the price of discrimination as the share of ingroup trades is increasing in price. Next, this figure shows that the share of ingroup trades experiences a large jump from left to right around zero in the market condition, which is less pronounced in the individual choice treatment. Here, the share of ingroup trades increases much more smoothly from left to right, which suggests that the payoff advantage is a more important decision criterion in the market than in the individual choice condition. That is, behavior in the market follows more closely the standard gametheoretic prediction. These findings are in line with the results shown in Table 2. An additional regression discontinuity analysis around the cutoff of 0 (that is, around the point where the best ingroup and the best outgroup offer yield the same payoff), reported in Table 3 , supports this insight: There is a significantly larger discontinuity in the market than in the individual choice condition (by a factor of almost 4) 17 Finally, it is noteworthy that there is a strong ingroup bias in the market when the costs are zero: The share of ingroup trades is $88.2 \%$ (compare Figure 11 in the Appendix) when the best ingroup offer equals the best outgroup offer (Best-In equals Best-Out).

\footnotetext{
${ }^{17}$ To be more precise, in the regression discontinuity estimation we use the ingroup minus the outgroup offer as a running variable and a cutoff of zero. We exclude observations at the cutoff, that is, observations for which this difference is zero. Furthermore, to estimate the endpoints next to the cutoff, we use local linear polynomial regressions with a triangular kernel. The order of the local polynomial used for the bias correction is quadratic and the bandwidth is selected via the approach of Calonico et al. (2014).
} 


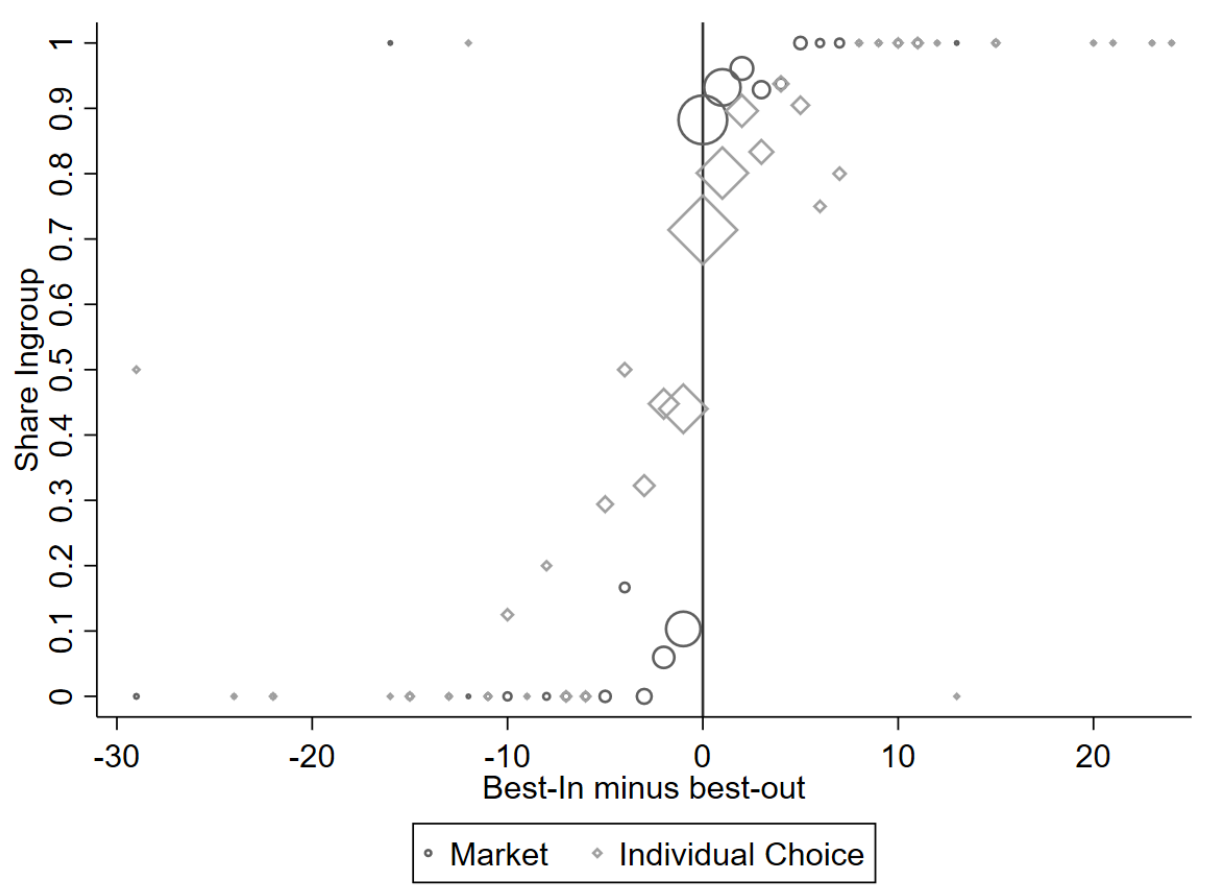

Figure 3: Share of ingroup buys on the y-axis and the payoff of the best ingroup option minus the payoff of the best outgroup option on the x-axis. The size of the markers is proportional to the number of observations.

\begin{tabular}{lcc}
\hline \hline RDD & Market & Individual Choice \\
\hline & $\begin{array}{r}0.81^{* * *} \\
(0.06)\end{array}$ & $\begin{array}{c}0.23^{* * *} \\
(0.08)\end{array}$ \\
\hline Bandwidth & 5.3 & 7.9 \\
$\mathrm{~N}$ & 37 & 37 \\
\hline \hline
\end{tabular}

Table 3: Regression discontinuity design in which the ingroup minus the outgroup offer serves as running variable with a cutoff of zero. The bandwidth is selected according to the approach of Calonico, Cattaneo, and Titiunik (2014). Local linear polynomial estimation with a triangular kernel. Robust standard errors in brackets below. *, **, *** indicate significance at the $10 \%$, $5 \%$ and $1 \%$ level, respectively. 


\subsection{Understanding Motivations of Decision-Makers}

To better understand the behavior of active subjects in the two treatments, we (i) document the frequency of choices that are in line with four different behavioral motives and (ii) estimate an individual choice model that allows us to quantify the relative importance of the decision-makers' payoff, social identity and egalitarian concerns.

Regarding (i), we study the following behavioral motives. The first is payoff maximization. We consider a choice to be in line with payoff maximization if the maximum available payoff in a given choice set is chosen. Second, we define a choice as best ingroup pick if the best (in monetary terms, from the point of view of the decision-maker) ingroup offer is chosen. Third, we denote a choice as being in line with equality-seeking behavior if the offer closest to 75 is chosen (since an offer of 75 would result in equal payoffs for the decision-maker and the recipient). Finally, we say a choice is in line with equality-seeking behavior ingroup if the ingroup offer closest to 75 is chosen. Of course, these four motives are not necessarily mutually exclusive as choices are potentially in line with several different motives at the same time. Therefore, the frequency of motives do not necessarily add up to $100 \%$ within treatments. It does, however, give an indication of how the market treatment changes the prevalent motives of behaviors relative to the individual choice situation 18 Classifying subjects' behavior according to these motives also enables us to check whether foregoing the payoff-maximizing option is motivated by identity-driven discrimination or by preferences for equality that are independent of identity.

Figure 4 displays the frequency of choices that are in line with each of the four motives by treatment. The top-left panel shows that the overwhelming majority of choices in the market treatment are in line with own money maximizing behavior. The share is more than 20 percentage points lower in the individual choice treatment (72\% versus $93 \%$ ). The frequency of choices in line with the best ingroup pick criterion is depicted in the top-right panel. Here the treatment difference is much smaller. Choices are around 4 percentage points less frequently in line with this motive in the individual choice condition as compared to the market. This difference is statistically significant at the $10 \%$ level. The two panels in the lower part of Figure 4 show an economically and statistically significantly higher prevalence of choices that are in line with equality-seeking behavior in the individual choice condition, both for the ingroup (with a difference of around 10 percentage points) and for non-group related equality (15 percentage points difference). Table 4 summarizes these results numerically. Overall, this analysis points to the conclusion that markets reduce discrimination through shifting preferences in the direction of more selfishness and diminished concerns for equality.

Regarding (ii), we estimate an alternative-specific conditional logit model (McFadden, 1974).

\footnotetext{
${ }^{18}$ We choose these motives because previous research has provided evidence that they are potentially relevant for choices. One of the first experimental studies to document the relevance of selfishness in markets is Smith (1962). The importance of egalitarian concerns in different economic games has been shown by Fehr and Schmidt (1999). Social group membership has been shown to matter in economic games by Chen and Li (2009). Müller (2019) finds that selfishness and equity-efficiency concerns interact in particular ways with social group membership.
} 

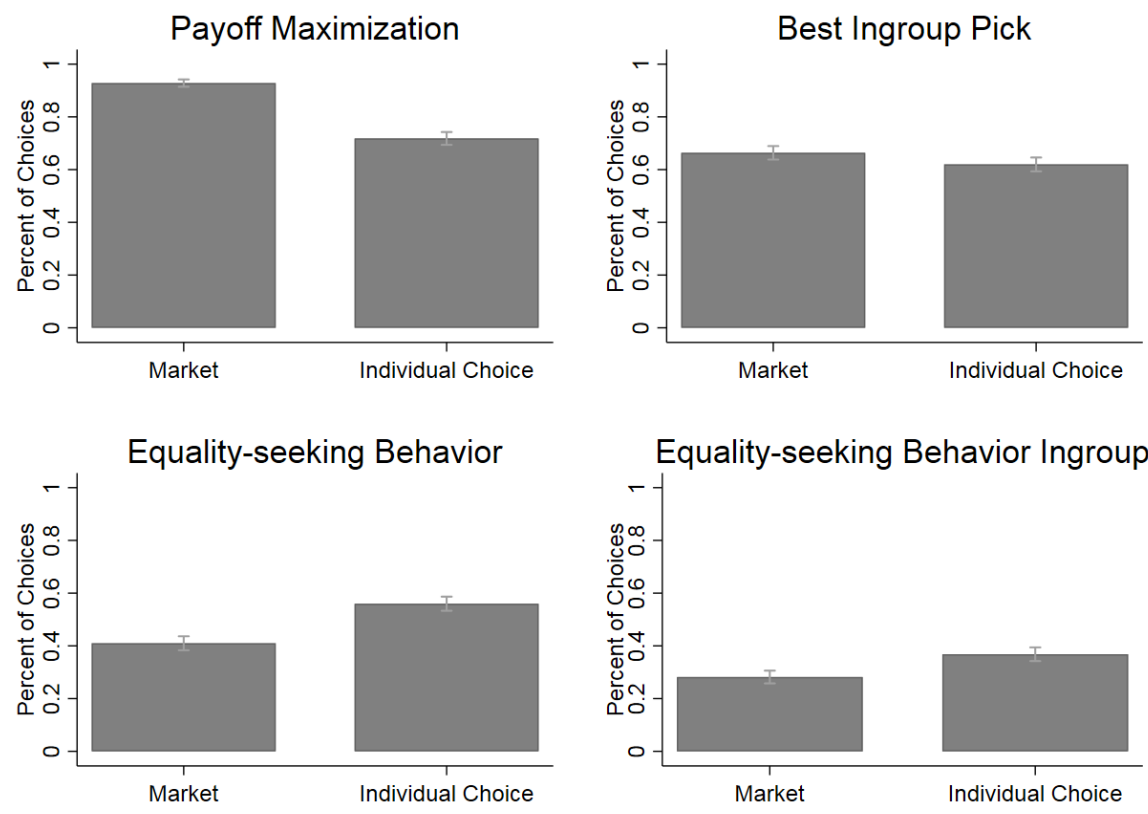

Figure 4: Number of choices in line with one of four motives by treatment. Bars indicate 95\% confidence intervals. All four panels are based on 354 choices that are available in both treatments in which Best-Out > Best-In.

We allow the utility of each option to depend on three arguments: own payoff, egalitarian preferences and the identity of the corresponding passive participant. That is, we assume here, unlike in the previous analysis above, that the three motives are independent parts of the utility function. In particular, we assume the following utility function

$$
u_{i t j}=\beta_{1} p a y_{i t j}+\beta_{2} i n_{i t j}+\beta_{3} e g_{i t j}+\left(\sum_{k=1}^{K} \alpha_{j k} z_{i t k}\right)+\varepsilon_{i t k},
$$

where $u_{i t j}$ is the utility of consumer $i$ in period $t$ from alternative $j$; pay is the payoff to consumer $i$ from alternative $j$; in is a dummy that is equal to 1 if the offer concerns an ingroup seller (recipient); $\mathrm{eg}$ is the closeness (the absolute distance) of the payoff to 75 and; finally, $\varepsilon$ is an error term. Since active participants face between two and six options, $j \in\{2, \ldots, 6\}$. The vector $z$ is a set of alternative-specific covariates. In our case $z$ consists of three control variables (a dummy that indicates whether the decision maker is female, age and the period of the experiment) that do not vary across cases. This model can be estimated assuming an extreme-value (Gumbel) distribution for the error term, resulting in a logit model.

Table 5 displays the results by treatment 19 We first run two regressions without eg, the equality variable, and then, in regressions (3) and (4), with all three components, that is, including the equality variable. All estimations are done including period, age and gender as

\footnotetext{
${ }^{19}$ Table 7 in the Appendix displays the same estimations only excluding the cases in which the best ingroup and the best outgroup option yield the same payoffs. The conclusions remain unchanged by this robustness check.
} 


\begin{tabular}{|c|c|c|c|}
\hline & Market & Individual Choice & Rank Sum Test \\
\hline \multirow[t]{2}{*}{ Payoff maximization } & 0.93 & 0.71 & $<0.001$ \\
\hline & {$[0.92,0.95]$} & {$[0.69,0.74]$} & \\
\hline \multirow[t]{2}{*}{ Best ingroup pick } & 0.68 & 0.64 & 0.07 \\
\hline & {$[0.65,0.70]$} & {$[0.61,0.67]$} & \\
\hline \multirow[t]{2}{*}{ Equality-seeking behavior } & 0.37 & 0.53 & $<0.001$ \\
\hline & {$[0.34,0.40]$} & {$[0.50,0.56]$} & \\
\hline \multirow[t]{2}{*}{ Equality-seeking behavior ingroup } & 0.26 & 0.35 & $<0.001$ \\
\hline & {$[0.23,0.28]$} & {$[0.32,0.38]$} & \\
\hline
\end{tabular}

Table 4: Frequency of motives. Overall frequency of choices that are in line with a specific motive. 95\% confidence interval in brackets below. The column "Rank Sum Test" indicates p-values for null hypothesis that data are from the same population. $N=2,266$.

case-specific controls, summarized in vector $z$. The "normalized" column after each estimation displays the estimated coefficients divided by the weight on the own payoff, thus allowing direct comparison of the relative weight on each motive. The results show that participants in the market treatment place the most weight on their own income. Subjects in the individual choice treatment on the other hand place the most weight on the identity of the passive subject (almost twice as much as on their own income). Egalitarian preferences (i.e. a preference for a payoff close to the equal split) also play a large role in the individual choice condition (the positive sign implies that subjects value payoffs closer to the equal split, everything else equal), but not in the market treatment (there, with a negative sign, which can be interpreted as competitive preferences). The inclusion of $e g$ barely affects the weight on the ingroup relative to the payoff variable. In summary, the estimation of choice models supports our previous conclusions that markets reduce discrimination by putting an increased focus on payoff maximization and a reduced weight on group identity of the trading partner. Moreover, this exercise allows us to precisely quantify the importance of different motives. Specifically, in the market, money maximizing is the single most important motive, whereas in the individual choice condition the identity of the passive subject is more important than are other motives. 


\begin{tabular}{|c|c|c|c|c|c|c|c|c|}
\hline & \multicolumn{2}{|c|}{ (1) } & \multicolumn{2}{|c|}{$(2)$} & \multicolumn{2}{|c|}{$(3)$} & \multicolumn{2}{|c|}{ (4) } \\
\hline & \multicolumn{2}{|c|}{ Market } & \multicolumn{2}{|c|}{ Individual Choice } & \multicolumn{2}{|c|}{ Market } & \multicolumn{2}{|c|}{ Individual Choice } \\
\hline & Estimates & Normalized & Estimates & Normalized & Estimates & Norm. & Estimates & Norm. \\
\hline Own payoff $\left(\beta_{1}\right)$ & $\begin{array}{l}1.50^{*} \\
(0.90)\end{array}$ & 1 & $\begin{array}{c}0.31^{* * *} \\
(0.06)\end{array}$ & 1 & $\begin{array}{c}1.57^{* *} \\
(0.70)\end{array}$ & 1 & $\begin{array}{c}0.40^{* * *} \\
(0.10)\end{array}$ & 1 \\
\hline Ingroup $\left(\beta_{2}\right)$ & $\begin{array}{c}0.99^{* * *} \\
(0.23)\end{array}$ & 0.66 & $\begin{array}{c}0.72^{* * *} \\
(0.15)\end{array}$ & 2.35 & $\begin{array}{c}1.04^{* * *} \\
(0.26)\end{array}$ & 0.66 & $\begin{array}{c}0.73^{* * *} \\
(0.15)\end{array}$ & 1.83 \\
\hline Egalitarian $\left(\beta_{3}\right)$ & $\begin{array}{l}- \\
-\end{array}$ & - & $\begin{array}{l}- \\
-\end{array}$ & - & $\begin{array}{c}-0.72^{* *} \\
(0.31)\end{array}$ & -0.46 & $\begin{array}{c}0.24^{* * *} \\
(0.08)\end{array}$ & 0.60 \\
\hline No-tradeoff & & es & & es & Yes & & $\mathrm{Ye}$ & \\
\hline Controls & & es & & es & Yes & & $\mathrm{Ye}$ & \\
\hline $\mathrm{N}$ & & 69 & & 69 & 5,16 & & 5,16 & \\
\hline Cases & & 81 & & 81 & 1,28 & & $1,2 \varepsilon$ & \\
\hline
\end{tabular}

Table 5: Conditional logit estimates. Standard errors, clustered at the subject level, in brackets below. ${ }^{*},{ }^{* *}, * * *$ indicate significance at the $10 \%, 5 \%$ and $1 \%$ level, respectively. Normalization: estimated equation times $\frac{1}{\beta_{1}}$.

\subsection{Questionnaire}

Next, we analyze the questions from the post-experimental questionnaire to better understand the channels through which the effect of markets on discrimination operates. Subjects were asked questions about their attitudes towards their own group, the way they made choices in the experiment and how relevant their group identity was for their choices. More specifically, the (translated) questions read as follows: (i) "I have fully identified with my group;" (ii) "Only my group membership was relevant for my decision;" (iii) "I made my decisions mainly to do something good for another member of my group;" (iv) "I made my decisions mainly to not harm another member of my group;" (v) "Only my own payout was relevant for my decision;" and (vi) "Both my own payout and the payout of the other person was relevant for my decision". All answer categories were given on a 5 point Likert-scale: "fully agree;" "rather agree;" "neither agree nor disagree;" "rather against;" "fully against;" and, "do not know". We code the answers between +2 ("fully agree") and -2 ("fully disagree"), whereby "neither agree nor disagree" and "do not know" are coded as 0.

The results are presented in Figure 5 below and in Table 8 in the Appendix. Questions (i) (iv) ask subjects about their identification with their own group. The answers to item (i) show that subjects in the market condition indicate weaker identification with their own group than do subjects in the individual choice condition. Furthermore, the answers to questions (ii) - (iv) show that markets reduce the importance of group membership, decrease altruism towards the ingroup, and decrease the desire "not to harm members of the own group at the expense of the outgroup'. In summary, all four comparisons consistently support the hypothesis that markets reduce attachment to one's social group. 
The evidence arising from questions (v) and (vi), on the other hand, illustrate a different mechanism: Markets render people more selfish, that is, they increase the importance of personal payments and decrease the focus on social identity and (ingroup-based) altruism. This evidence is hence also in line with the conclusions presented before in the current as well as in other papers (Falk and Szech, 2013; Bartling, Weber, and Yao, 2014), showing that markets erode social motives. To summarize, we interpret the findings from the questionnaire as evidence that markets diminish discrimination by increasing selfishness and decreasing social motivations.

(I) Identification
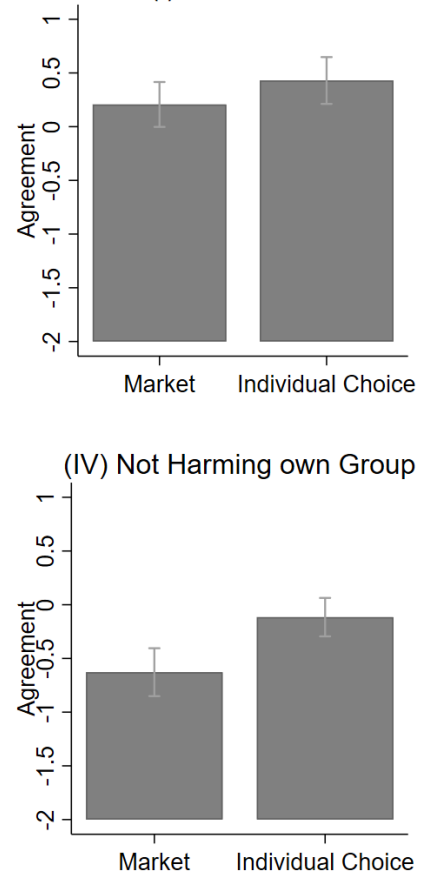

(II) Importance of Group
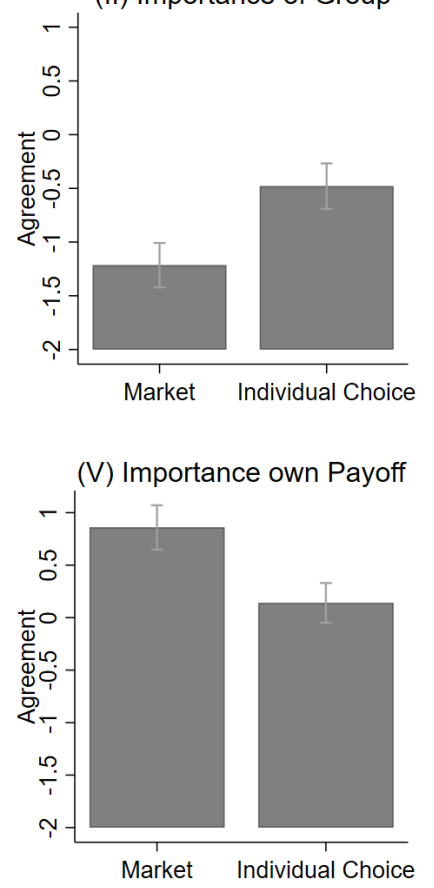

(III) Support for Group

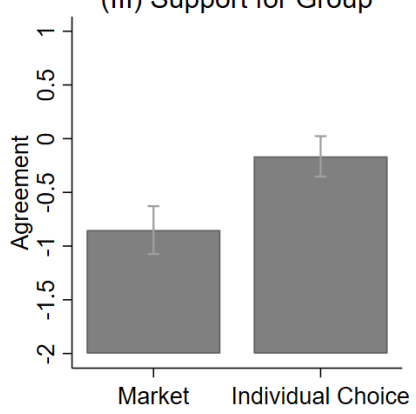

(VI) Altruism

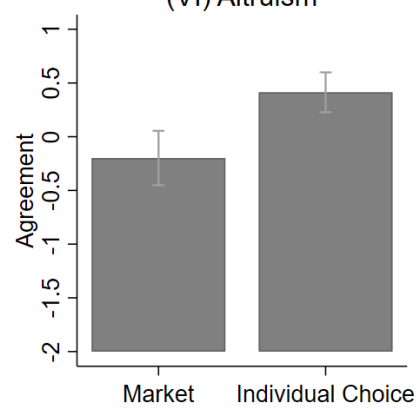

Figure 5: Average answers to exit survey questions by treatment plus $95 \%$ confidence intervals.

\subsection{Beliefs of Passive Subjects}

Finally, we turn to the examination of beliefs of passive subjects (recipients or sellers) concerning the behavior of decision-makers. In particular, we examine whether passive subjects expect the increased focus on group identity in the individual choice condition beforehand. To analyze this question, we make use of data on the (un-incentivized) beliefs of passive subjects. We elicit beliefs in every period, while they waited for the choices of active subjects. Specifically, the (translated) version of the question in the market treatment reads as follows: "What percentage of buyers during this period do you think considers which group (Klee or Kandinsky) the seller comes from when making their purchase decision?". And in the individual choice situation: "What percentage of participants B during this period do you think, when deciding on the distribution, 
also pay attention to which group (Klee or Kandinsky) participant A comes from?"20 Figure 6 displays the results.

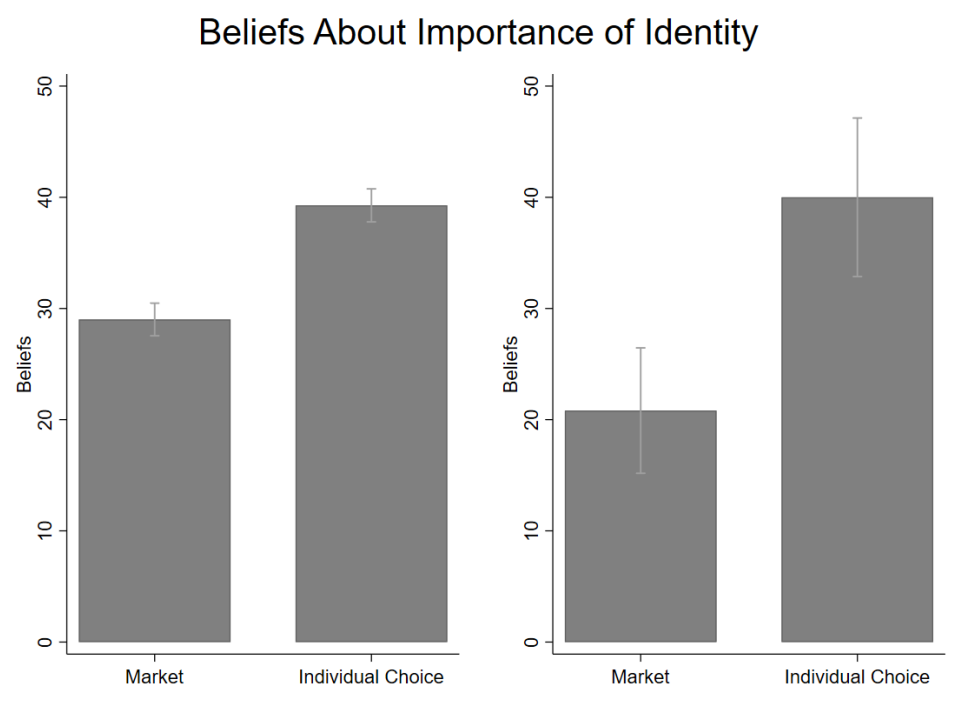

Figure 6: Average answers to the question "What percentage of buyers [dictators] do you believe care about your identity?" and $95 \%$ confidence intervals. The left-hand panel $(N=3,168)$ shows beliefs across all periods. The right-hand panel $(N=132)$ shows the beliefs for the first period only, that is, before any feedback was received.

The average answer in the market treatment over all periods is $29.0 \%$ with a $95 \%$ confidence interval of $[27.6,30.5]$. The same number in the individual choice condition is $39.3 \%$ with a confidence interval of $[37.8,40.7]$, see the left panel of Figure 6. Thus, the difference in beliefs is about 10 percentage points, which is large and statistically significant (Wilcoxon rank sum test, $p<0.01)$. It is also instructive to look only at beliefs in the first period, because at this stage passive subjects have not yet received any feedback about the behavior of decision-makers. It turns out that the average belief is $20.8 \%$ with a $95 \%$ confidence interval of $[15.2,26.5]$ in the market and $40.0 \%$, with a confidence interval of [32.9, 47.2], in the individual choice treatment (compare right panel of Figure 6). Hence, the average beliefs held about the share of people who care about their social group is about twice as large in individual choice treatment as compared to the market treatment. Again, the Wilcoxon rank sum test clearly detects significant differences $(p<0.01)$. To sum up, the evidence presented in this sub-section revealed astonishing results: it turns out that subjects anticipate the behavioral changes induced by the treatments. We interpret this finding as evidence that subjects anticipate different norms of behavior.

\footnotetext{
${ }^{20}$ Since passive participants were never informed about the identity of buyers, belief elicitation could therefore not be influenced by information about buyer's identity from previous periods.
} 


\section{Robustness Checks and Discussion}

In this section, we present various robustness checks, including an additional laboratory experiment that varies the design of the decision screens in Section 4.1. Section 4.2 presents the online experiment. Section 4.3 discusses concerns about external validity, exploiting List's (2020) SANS framework.

\subsection{Additional Laboratory Experiment and Other Robustness Checks}

Once a buyer accepts an offer in the market, this offer is no longer available to other buyers. We compare decisions in the last round of each period, in which no further interactions between buyers is possible, to test whether such a possible strategic interaction confounds our results. Figure 9 in Appendix A.1 shows the share of ingroup buys for the last buyers only. The treatment difference in the last round is almost identical to the average over all rounds $(31.7 \%$ versus $0 \%)$. Thus, concerns about strategic interactions seem to be unfounded. Moreover, Figure 10 in Appendix A.1 displays the results for first round buyers only (and their corresponding individual choice controls). This difference is again around 30 percentage points (14\% versus $44 \%$ ). We interpret this pattern as evidence that neither differences in the order of decisions nor specific strategic or reciprocal motives are able to offer an alternative explanation for our main finding.

The design of the decision screens in both the market and the individual choice conditions in the main experiment follows closely that of Bartling, Weber, and Yao (2014). However, one concern might be that the individual choice condition points to the payoff of the passive subject by displaying individual payoffs for both the active and the passive subject. In contrast, the market might point to the price and therewith to the active subjects' payoff. We take the data from three of our market sessions and construct an additional individual choice control treatment in which we do not display the payoffs of the passive subjects ${ }^{21}$ Figure 12 and Figure 13 in Appendix A.2 present the results from this robustness check. The treatment difference is again significant, although somewhat smaller (around 20 percentage points), and findings are in line with previous conclusions. Additionally, Figure 14 in Appendix A.2 displays the relation of the price of prejudice and the share of ingroup trades for both treatments in this robustness check. This graph again shows the same patterns in the data as the main experiment. That is, the price of prejudice is relevant in both treatments, but less so in the individual choice condition. We take these findings as evidence that the presentation of the results does not drive the treatment effect.

\subsection{Online Experiment}

In addition to the laboratory experiments, we also conduct an online experiment with a heterogeneous sample and natural identities. This online experiment relies on the same two treatments:

\footnotetext{
${ }^{21}$ Sessions were held in August 2020 in the WISO laboratory at the University of Hamburg.
} 
the framing of a decision task either in terms of a market or in terms of a neutral allocation task. Relative to the laboratory, the online survey experiment varies several dimensions. First, we invite a heterogeneous sample of citizens of Berlin and Cologne, two large German cities, instead of a student sample. The age of active participants ranges from 21 to 73 years with an average age of 48 (50\% of participants are female). Around one third of the participants has a university degree (but only $5 \%$ of subjects are currently university students), one third has a high school diploma, and another third completed lower secondary education. Second, instead of artificial, random groups, we use natural groups: the residents of the two cities. We choose two different cities because it is well-known that regional identities are among the strongest (Lane, 2016). Our conjecture is that in a setting with high ingroup favoritism, framing has a smaller effect which in turn makes the online experiment a tougher test for the market hypothesis. Ultimately, however, whether this conjecture is true is an empirical question. We thus view the online experiment not only as a robustness check for the laboratory experiment, but also as a contribution in itself as it allows to compare discrimination in random and natural groups within the same framework. Third, subjects do not necessarily participate in the online experiment at the same time. That is, the online market might, in fact, have more the character of a survey than an interactive market. We suspect that this approach takes away part of the "competitiveness" of the online market which in turn could lead to a lower treatment effect, too. Fourth, the market in the online experiment takes away any remaining potential for strategic (pseudo-) interactions as the number of available offers is always two and prizes are not determined by choices in the online survey itself (instead, prices are random draws, as we will explain below). We believe all four modifications stack the deck against finding a treatment effect.

Before we turn to the results of this online experiment, we mention some logistical details first. When entering the survey, subjects were randomized to either the market treatment or the individual choice condition. We used the same wording as in the laboratory experiment to induce framing. The randomization was done within each city such that half of the participants from Berlin and half of participants from Cologne took part in either treatment (however, due to attrition, not perfectly so). Within each treatment, subjects were randomized into the role of active or passive participants. Like the laboratory, the online experiment went on for 24 periods again, one period was randomly chosen to be payoff relevant. In order to minimize the complexity of the online experiment, only one ingroup and one outgroup offer was available (hence, for all active participants, one offer always came from Berlin and one from Cologne). It was not possible for participant to abstain from buying an offer. Like in the laboratory experiment, the payoff for the seller was given by 50 plus the price, and the payoff for buyer by 100 minus the price. The prices of the two goods were the results of two discrete uniform i.i.d. draws from $p \in\{2,4,6, \ldots, 46,48\}$, that is, multiples of 222

\footnotetext{
${ }^{22}$ Sample screens of the decision screens in the online survey experiment for both treatments can be found in the Appendix A.9 The online experiment was conducted in December 2020. The experiment was programmed using oTree (Chen, Schonger, and Wickens, 2016). A session lasted on average 25 minutes. The exchange rate
} 
All in all, we analyze choices of 26 buyers in the market condition and 29 dictators in the individual choice condition. Like in the laboratory experiment, passive participants served as recipients for payoffs in both conditions. In total, we thus gathered 1,320 observations (55 active subjects $\times 24$ periods), 624 in the market and 696 in the individual choice condition. Out of these 1,320 observations, 643 are situations in which the outgroup offer delivers a larger payoff to the active participant than the ingroup offer.

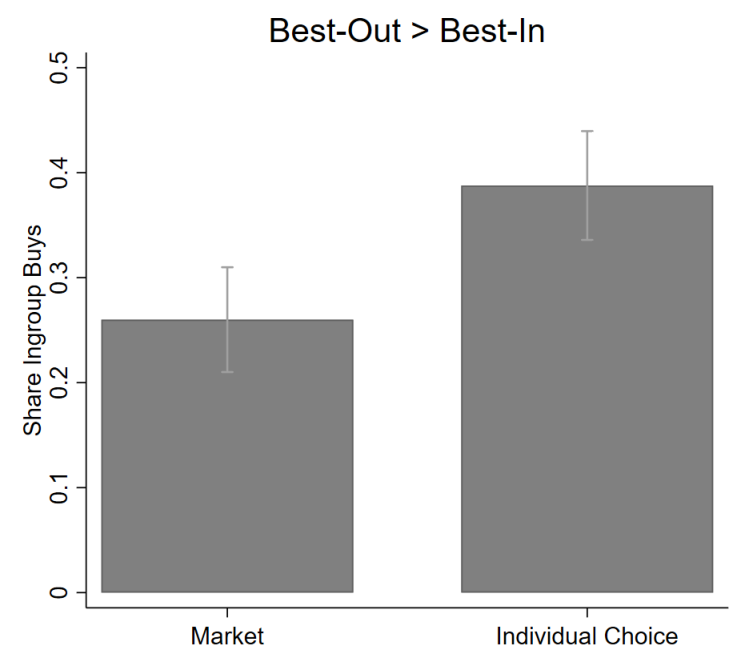

Figure 7: Online Experiment. Share of ingroup buys in situations in which the outgroup option is cheaper than the ingroup option. $N=300$ in the market and $N=343$ in the individual choice condition. The means are $26.0 \%$ in the market and $38.8 \%$ in the individual choice condition. Bars around the means indicate $95 \%$ confidence intervals.

Figure 7 presents the main result. The average share of ingroup buys is $26 \%$ in the market and $39 \%$ in the individual choice condition. The economic effect size is thus around 13 percentage points. A ranksum test confirms statistical significance with a p-value below 1\%. Moreover, Figure 8 displays the relation of the price of prejudice and the frequency of ingroup trades. Again, the main pattern is confirmed in the data, although the baseline level of ingroup trades is higher in the online experiment. Summing up, findings in the online experiment corroborate our main effect.

While the treatment effect is smaller than in the main experiment, the two effect sizes are not easily comparable due to a different number of offers, different incentives and, as mentioned above, due to the variation of other experimental parameters. One insightful way to compare behavior in the online and the main experiment is via the calculation of a "willingness-to-pay" (WTP) for discrimination. Specifically, we observe that subjects forgo on average 5.93 tokens per choice, in the 343 choices in which discrimination was possible, in the individual choice was such that 1 Euro equaled 10 tokens (instead of 1:5 like in the laboratory experiment). We utilized the online research panel from the company "Consumerfieldwork" which is an actively-managed panel and is solely used for research purposes. 


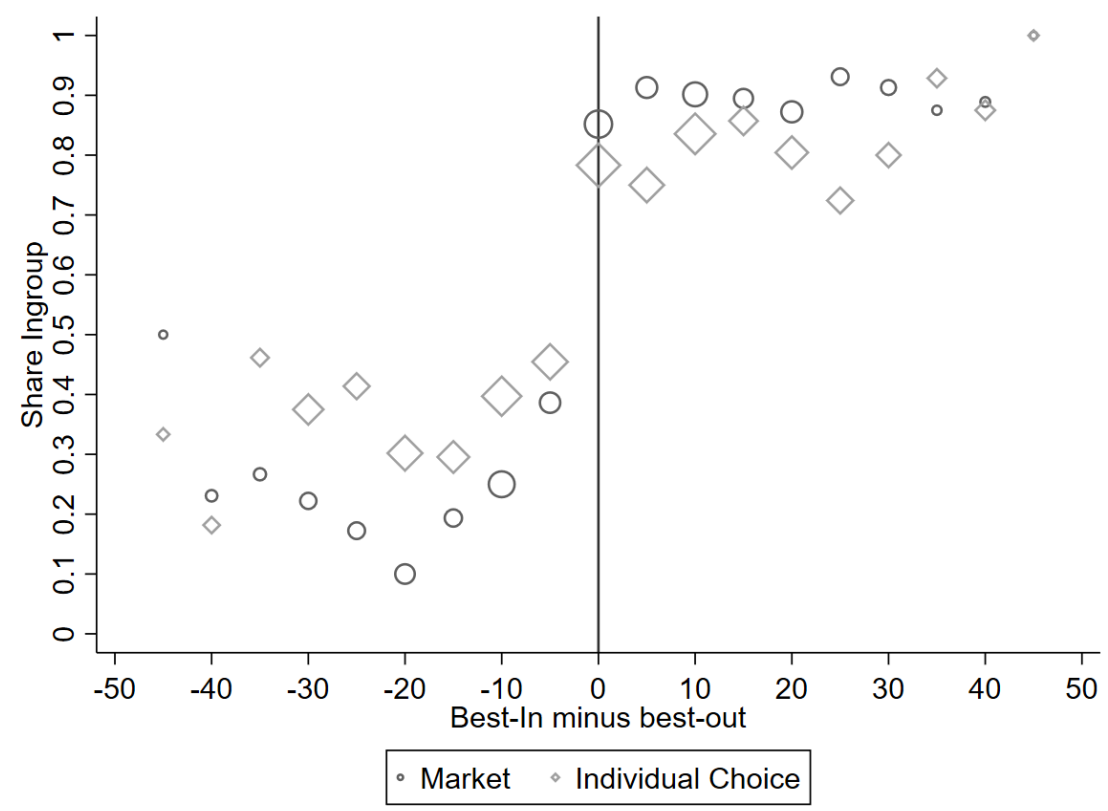

Figure 8: Online Experiment. Share of ingroup buys on the y-axis and the payoff of the best ingroup option minus the payoff of the best outgroup option on the x-axis. The size of the markers is proportional to the number of observations. The payoff differences are rounded to the nearest multiple of five.

condition and 3.88 tokens in the market (300 choices) in order to avoid an outgroup trade. Considering the main lab experiment, the same numbers are 2.57 tokens in the individual choice condition and 0.15 tokens in the market.

\begin{tabular}{lcc}
\hline \hline & Individual Choice & Market \\
\hline Online & 0.59 & 0.38 \\
Laboratory & 0.51 & 0.03 \\
\hline \hline
\end{tabular}

Table 6: Willingness-to-pay to discriminate by experiment and treatment, in euros.

Table 6 summarizes these results after converting tokens into euros (the exchange rates was 5:1 in the laboratory experiment and 10:1 in the online experiment). Participants have on average a higher willingness-to-pay to discriminate against different geographic groups than against artificial random groups - a finding that is in line with Lane (2016). Moreover, the difference between both treatments is lower in the online experiment (21 cents vs 48 cents).

However, it is also important to note that the numbers in the online experiment are likely too high relative to the laboratory experiment for at least two reasons. First, in the online experiment opportunities for discrimination are higher because the payoff differences are larger on average (up to 48 tokens). Thus, the upper bound on the WTP that can be measured is higher 
online. Second, the data from the online experiment likely exhibits more noise. If, for instance, a certain fraction of participants chooses randomly than the share of ingroup trades in Figure 8 will be upward biased in the negative domain and downward biased in the positive domain. In fact, the data from the online experiment seem consistent with this idea since the shares of ingroup trades in the positive domain are around 80\%-90\% with no visible upward trend and thus not as close to $100 \%$ as one would expect with a strong ingroup bias. This insight in turn also implies that the treatment effect in the online experiment is downward biased relative to the laboratory experiment (because the pull towards the middle is stronger for ingroup shares closer to zero or one).

\subsection{External validity and the SANS conditions}

Finally, we follow List's (2020) SANS conditions (selection, attrition, naturalness and scaling) to address concerns about external validity. First, in terms of selection, a student sample participated in the laboratory experiment. A sample of residents of two German cities participated in the online survey experiment. Assignment to treatment was random for both samples. There is no attrition as all participants follow the laboratory experiment until the very end. In the online experiment, fourteen participants in Berlin and ten in Cologne did not complete the survey. These observations were consequently not included into the dataset. Considering the naturalness of the decision task, we use a laboratory experiment in the main part of the paper. Thus our setting is rather artificial. However, both the market and the individual choice condition are standardized and established experiments. List (2009), for example, finds that qualitative insights from a laboratory experiment are transferable to a natural environment ${ }^{23}$ The online survey on the other hand might be more natural because decision makers can chose between buying from a local or a non-local seller, which might be more familiar to them. Finally, in terms of scaling, Lane (2016) provides evidence that discrimination between artificial groups is (i) bounded by discrimination between different natural groups and (ii) lower than discrimination of different regional groups. These findings are corroborated by our results. The results of List (2009) in combination with the fact that the market hypothesis works with both natural groups in an online experiment and with random groups in the laboratory highlight the potential of markets to reduce discrimination in the field.

\section{Concluding Remarks}

While a topic of heated debate and recognized as an important societal problem, little is known about how to fight discrimination. In this study, we show that markets can offer a remedy. Our laboratory experiment exogenously manipulates the institutional framework in which the trade

\footnotetext{
${ }^{23}$ Compare Al-Ubaydli, List, and Suskind (2017) and Levitt and List (2007) for a general discussion of external validity of experiments.
} 
takes place, while at the same time tightly controlling economic incentives and group identity. Thus, the current study identifies the causal effect of markets on discrimination. We find strong evidence for an economically and statistically significant reduction of the frequency of ingroup trades in markets in situations in which the outgroup offer yields a higher payoff. Notably, this reduction takes place relative to individual choice situations with the same payoff structure and the same identity of the trading partner.

Moreover, we are able to estimate the responsiveness of discrimination to the "price of prejudice" (the relative payoff advantage of the outgroup offer), to borrow the words of Gary Becker (1957). The observed choices in the experiment reveal that decision-makers act as if they are making rational trade-offs between payoffs and discriminatory actions. In the market, subjects pay close attention to the price of discrimination and behave in a discriminatory manner when the price is zero. In the individual choice condition, subjects also heed the price of discrimination, but display a greater willingness-to-pay to conduct an ingroup trade and also display more choices that can be rationalized as egalitarian concerns. Thus, our experiment shows that discriminators rationally react to prices, which in turn is important in designing effective policies to clamp down on discrimination.

The finding that markets make people more selfish is in line with studies that show that markets erode social motivations (Falk and Szech, 2013; Bartling, Weber, and Yao, 2014). Additionally, we identify two further channels that drive the main effect. We find that markets reduce identification with one's group, which in turn leads to a reduction of choices that go at the expense of the outgroup. Finally, we find that markets reduce aversion to inequality. Support for these different channels is provided not only in post-experimental survey questions, but also when we estimate a choice model that simultaneously allows different behavioral motives to play a role.

These results are particularly remarkable because little evidence exists that shows how to reduce discrimination. At the same time, they open up potentials for policy interventions such as the introduction of markets and increasing the price of prejudice, be it through actual competition or via a framing that introduces a market context. One major advantage of such a policy intervention - relative to other proposals like the "contact hypothesis" (Allport, 1954) - is the fact that it does not necessarily rely on people self-selecting into treatment. Selection is likely biased, with more open-minded, less-discriminatory individuals being more likely to take part in such anti-prejudice interventions, which could in turn reduce their usefulness. Instead, the fostering of markets in different areas hardly relies on self-selection and is thus more broadly applicable. Another advantage are the low monetary costs of implementing a competitive framework.

It is noteworthy that our main result does not only rely on the mechanism initially suggested by Becker (1957), namely that markets increase the price for discrimination by fostering competition. Instead, the experiment shows that a market framing can change behavior in predictable ways: conditional on the price of discrimination, discrimination is lower in markets than in 
comparable, neutrally-framed choice situations. Our findings suggest that the additional effect of competition (i.e. higher costs of discrimination) would further increase the main effect since subjects in markets are more price-sensitive. Furthermore, it is also important to bear in mind that markets display significant discrimination in situations in which the costs of doing so are zero. That is, markets do not stifle discrimination per se, but instead work by increasing selfishness. This finding also suggests that discrimination might persist in fully competitive markets in which discrimination is costless for buyers. Our experiment's main take-away message is thus that the price of prejudice matters and that any intervention that boosts the focus on personal monetary gains might help fight this societal harm.

While it was previously recognized that markets tend to increase selfishness and decrease moral behavior, our study shows that in some circumstances this can benefit society. Our paper thus provides evidence for the bright side of markets - a facet of markets already highlighted by Voltaire more than two centuries ago.

\section{References}

Akerlof, G. (1970): "The market for "Lemons": Quality uncertainty and the market mechanism," Quarterly Journal of Economics, 84(3), 488-500.

Al-Ubaydli, O., J. A. List, and D. L. Suskind (2017): "What can we learn from experiments? Understanding the threats to the scalability of experimental results," American Economic Review, 107(5), 282-86.

Allport, G. W. (1954): The nature of prejudice. Addison-Wesley Reading, MA.

Atkin, D., E. Colson-Sinra, and M. Shayo (2021): "How do we choose our identity? a revealed preference approach using food consumption," Journal of Political Economy, forthcoming.

Ayres, I., M. BanaJi, and C. Jolls (2015): "Race effects on eBay," The RAND Journal of Economics, 46(4), 891-917.

Bartling, B., E. Fehr, and Y. Özdemir (2020): "Does market interaction erode moral values?," Available at SSRN.

Bartling, B., M. Grieder, and C. Zehnder (2017): "Competitive pricing reduces wasteful counterproductive behaviors," Journal of Public Economics, 156, 34-47.

BARTLING, B., And Y. Özdemir (2017): "The limits to moral erosion in markets: Social norms and the replacement excuse," Working Paper.

Bartling, B., R. A. Weber, And L. Yao (2014): "Do markets erode social responsibility?," The Quarterly Journal of Economics, 130(1), 219-266. 
Becker, G. S. (1957): "The Economics of Discrimination," University of Chicago Press Economics Books.

Bertrand, M., and E. Duflo (2017): "Field experiments on discrimination," in Handbook of economic field experiments, vol. 1, pp. 309-393. Elsevier.

Bock, O., I. Baetge, And A. Nicklisch (2014): "hroot: Hamburg registration and organization online tool," European Economic Review, 71, 117-120.

Cacault, M. P., and M. Grieder (2019): "How group identification distorts beliefs," Journal of Economic Behavior 83 Organization, 164, 63-76.

Calonico, S., M. D. Cattaneo, and R. Titiunik (2014): "Robust nonparametric confidence intervals for regression-discontinuity designs," Econometrica, 82(6), 2295-2326.

Chen, D. L., M. Schonger, and C. Wickens (2016): "oTree-An open-source platform for laboratory, online, and field experiments," Journal of Behavioral and Experimental Finance, 9, 88-97.

Chen, R., And Y. Chen (2011): "The potential of social identity for equilibrium selection," American Economic Review, 101(6), 2562-89.

Chen, Y., And S. X. Li (2009): "Group identity and social preferences," American Economic Review, pp. 431-457.

Cooke, D., A. P. Fernandes, and P. Ferreira (2019): "Product market competition and gender discrimination," Journal of Economic Behavior \& Organization, 157, 496-522.

Cornaglia, F., M. Drouvelis, and P. Masella (2019): "Competition and the role of group identity," Journal of Economic Behavior \&3 Organization, 162, 136-145.

Doleac, J. L., and L. C. Stein (2013): "The visible hand: Race and online market outcomes," The Economic Journal, 123(572), F469-F492.

Falk, A., And N. Szech (2013): "Morals and markets," Science, 340(6133), 707-711.

Fehr, E., And K. M. Schmidt (1999): "A theory of fairness, competition, and cooperation," Quarterly Journal of Economics, pp. 817-868.

FischBACHER, U. (2007): "z-Tree: Zurich toolbox for ready-made economic experiments," Experimental economics, 10(2), 171-178.

Friedman, M. (1962): Capitalism and freedom. University of Chicago press.

Hargreaves Heap, S. P., and D. J. Zizzo (2009): "The value of groups," American Economic Review, 99(1), 295-323. 
Hedegaard, M. S., and J.-R. Tyran (2018): "The price of prejudice," American Economic Journal: Applied Economics, 10(1), 40-63.

Henrich, J., J. Ensminger, R. McElreath, A. Barr, C. Barrett, A. Bolyanatz, J. C. Cardenas, M. Gurven, E. Gwako, N. Henrich, et Al. (2010): "Markets, religion, community size, and the evolution of fairness and punishment," science, 327(5972), 1480-1484.

HuCK, S., G. K. Lünser, And J.-R. Tyran (2012): "Competition fosters trust," Games and Economic Behavior, 76(1), 195-209.

Irlenbusch, B., And D. J. SAXler (2019): "The role of social information, market framing, and diffusion of responsibility as determinants of socially responsible behavior," Journal of Behavioral and Experimental Economics, 80, 141-161.

Kirchler, M., J. Huber, M. Stefan, and M. Sutter (2015): "Market design and moral behavior," Management Science, 62(9), 2615-2625.

Lane, T. (2016): "Discrimination in the laboratory: A meta-analysis of economics experiments," European Economic Review, 90, 375-402.

Le Coq, C., J. Tremewan, and A. K. Wagner (2015): "On the effects of group identity in strategic environments," European Economic Review, 76, 239-252.

Levitt, S. D., And J. A. List (2007): "What do laboratory experiments measuring social preferences reveal about the real world?," The Journal of Economic Perspectives, 21(2), 153174.

Li, H., K. Lang, and K. Leong (2017): "Does Competition Eliminate Discrimination? Evidence from the Commercial Sex Market in Singapore," The Economic Journal, 128(611), 1570-1608.

Li, S. X., K. Dogan, and E. Haruvy (2011): "Group identity in markets," International Journal of Industrial Organization, 29(1), 104-115.

List, J. A. (2004): "The nature and extent of discrimination in the marketplace: Evidence from the field," The Quarterly Journal of Economics, 119(1), 49-89.

(2009): "The economics of open air markets," Discussion paper, National Bureau of Economic Research.

(2020): "Non est Disputandum de Generalizability? A Glimpse into The External Validity Trial," Discussion paper, National Bureau of Economic Research.

List, J. A., W. S. Neilson, And M. K. Price (2016): "The effects of group composition in a strategic environment: Evidence from a field experiment," European Economic Review, 90, $67-85$. 
MCFADDEn, D. (1974): "Conditional logit analysis of qualitative choice behavior," Frontiers in Econometrics.

MÜLLER, D. (2019): "The anatomy of distributional preferences with group identity," Journal of Economic Behavior \& Organization, 166, 785-807.

Paetzel, F., and R. Sausgruber (2018): "Cognitive ability and in-group bias: An experimental study," Journal of Public Economics, 167, 280-292.

PAGer, D. (2016): "Are firms that discriminate more likely to go out of business?," Sociological Science, 3, 849-859.

Phelps, E. S. (1972): "The statistical theory of racism and sexism," The american economic review, 62(4), 659-661.

Sмiтh, V. L. (1962): "An experimental study of competitive market behavior," Journal of Political Economy, 70(2), 111-137.

Sutter, M., J. Huber, M. Kirchler, M. Stefan, and M. Walzl (2016): "Where to Look for the Morals in Markets?," Experimental Economics, pp. 1-23.

TAJfel, H., And J. C. Turner (1979): "An integrative theory of intergroup conflict," The social psychology of intergroup relations, 33(47), 74 .

VARIAn, H. R. (1985): "Price discrimination and social welfare," The American Economic Review, 75(4), 870-875.

Weber, A., And C. Zulehner (2014): "Competition and gender prejudice: Are discriminatory employers doomed to fail?," Journal of the European Economic Association, 12(2), 492-521.

Xu, X., J. Potters, and S. Suetens (2020): "Cooperative versus competitive interactions and in-group bias," Journal of Economic Behavior \& Organization, 179, 69-79. 


\section{A Appendix}

\section{A.1 Additional Results: Figures}

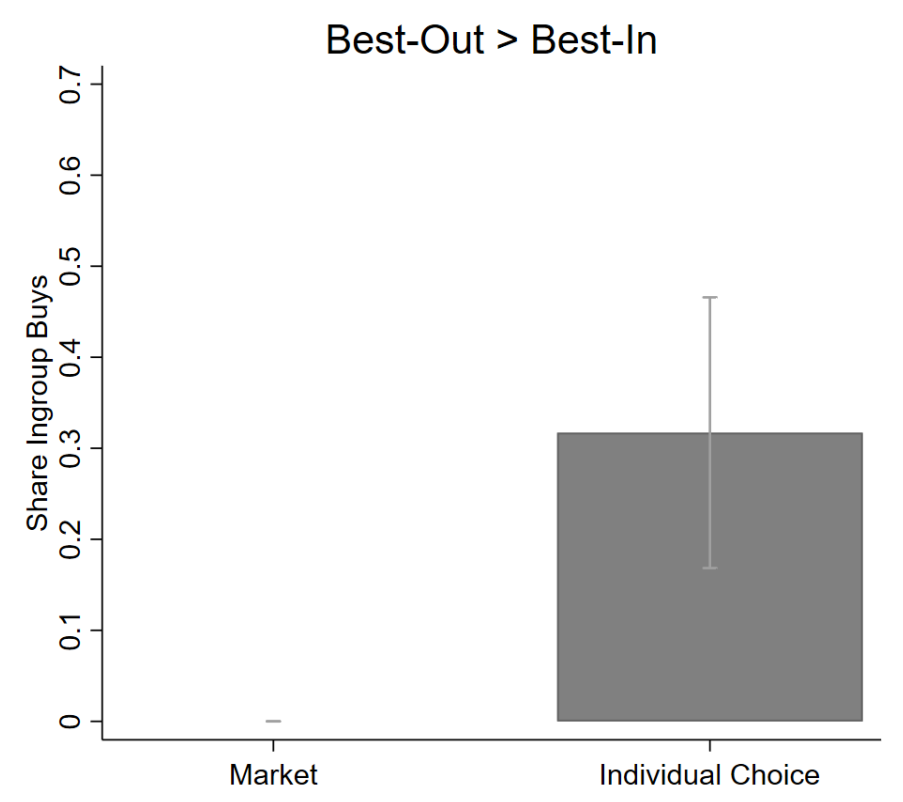

Figure 9: Share of ingroup buys in situations in which the best outgroup option is cheaper than the best ingroup option by last-round buyers only. $N=41$ in each treatment. The means are $0.0 \%$ in the market and $31.7 \%$ in the individual choice condition. Bars around the means indicate $95 \%$ confidence intervals.

Figure 11 displays additional results for the cases in which payoff of the best ingroup option minus payoff of the best outgroup option is positive (Figure 11, left panel) and zero (right panel). We find that in cases in which payoff maximization and ingroup favoritism both predict buying from an ingroup seller, the share of ingroup buys is higher in the market treatment than in the individual choice condition $(83.7 \%$ versus $73.4 \%)$. In situations in which both options deliver the same payoffs, buyers in the market more often choose the ingroup option than do dictators in the individual choice condition (88.2\% versus $70.1 \%)$. A Wilcoxon test detects statistically significant differences at the $1 \%$ level in both cases. Note that both situation are not suitable for detecting costly discrimination because the situations in the left panel do not capture discrimination and situations in the right panel have no differences in costs. In the following section, we analyze individual behavior in more detail to improve our understanding of the underlying motivations of decision-makers. 


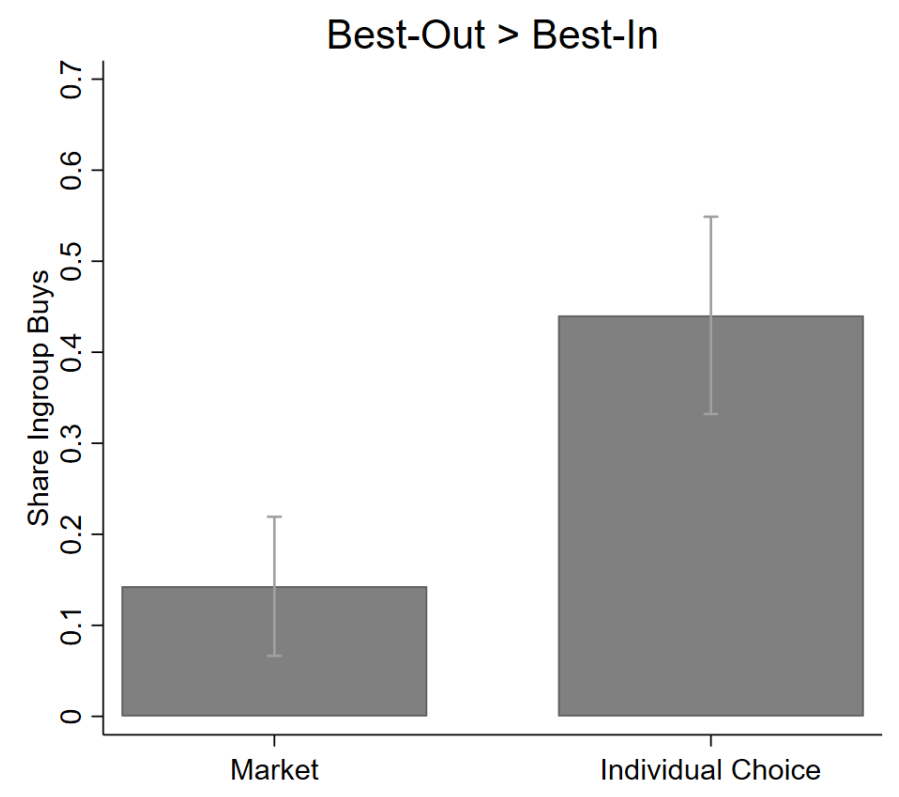

Figure 10: Share of ingroup buys in situations in which the best outgroup option is cheaper than the best ingroup option by first-round buyers only. $N=84$ in each treatment. The means are $14.2 \%$ in the market and $44.0 \%$ in the individual choice condition. Bars around the means indicate $95 \%$ confidence intervals.
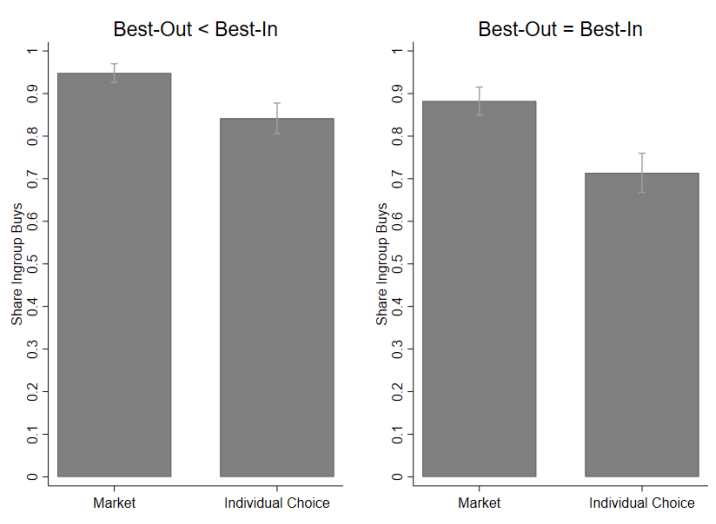

Figure 11: Share of ingroup buys. Left-hand panel: $N=405$; the means are $94.8 \%$ in the market and $84.1 \%$ in the individual choice condition. Right-hand panel: $N=374$; the means are $88.2 \%$ in the market and $71.4 \%$ in the individual choice condition. 


\section{A.2 Additional Results: Control Session}

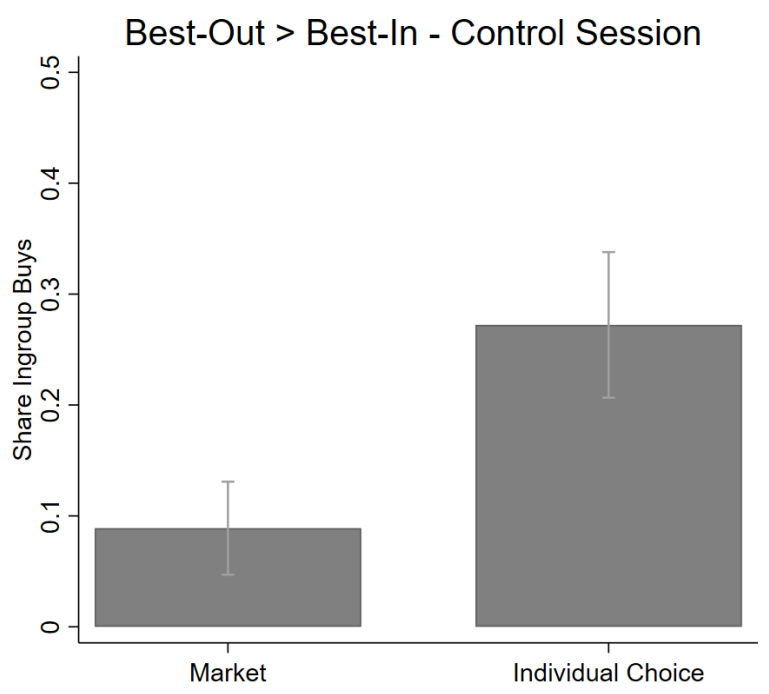

Figure 12: Control Session. Share of ingroup buys in control session; $N=180$. The means are $8.1 \%$ in the market and $27.2 \%$ in the individual choice condition.
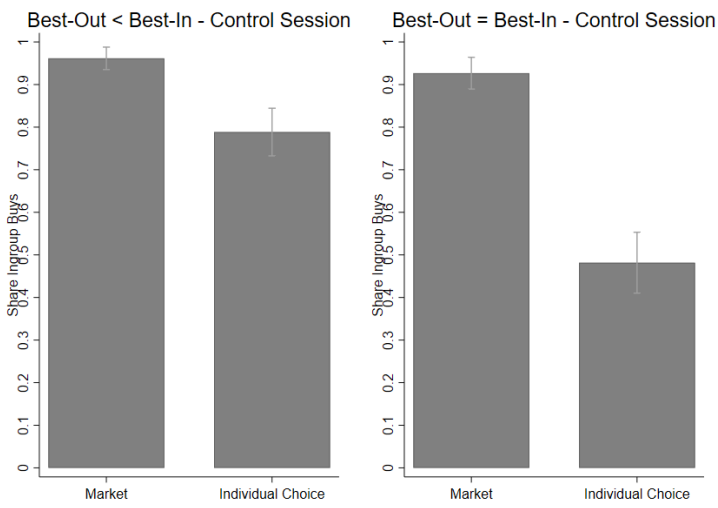

Figure 13: Control Session. Share of ingroup buys. Left-hand panel: $N=208$; the means are $96.2 \%$ in the market and $78.8 \%$ in the individual choice condition. Right-hand panel: $N=191$; the means are $92.7 \%$ in the market and $48.2 \%$ in the individual choice condition. 


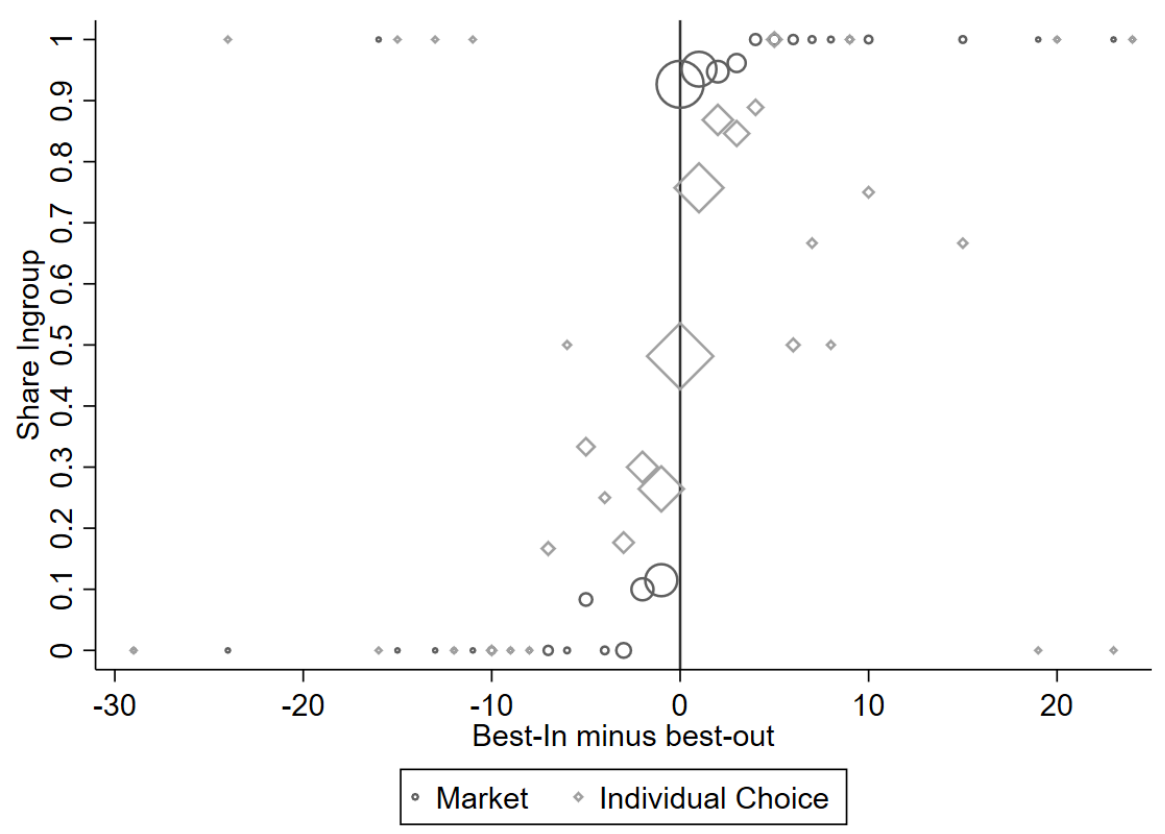

Figure 14: Control Session. Share of ingroup buys on the y-axis and the payoff of the best ingroup option minus the payoff of the best outgroup option on the x-axis. The size of the markers is proportional to the number of observations.

\section{A.3 Additional Results: Logit Model}




\begin{tabular}{|c|c|c|c|c|c|c|c|c|}
\hline & \multirow{2}{*}{\multicolumn{2}{|c|}{$\begin{array}{c}(1) \\
\text { Market }\end{array}$}} & \multicolumn{2}{|c|}{$(2)$} & \multicolumn{2}{|c|}{$(3)$} & \multicolumn{2}{|c|}{$(4)$} \\
\hline & & & \multicolumn{2}{|c|}{ Individual Choice } & \multicolumn{2}{|c|}{ Market } & \multicolumn{2}{|c|}{ Individual Choice } \\
\hline & Estimates & Normalized & Estimates & Norm. & Estimates & Norm. & Estimates & Norm. \\
\hline Own payoff $\left(\beta_{1}\right)$ & $\begin{array}{c}1.27 \\
(0.90)\end{array}$ & 1 & $\begin{array}{c}0.22^{* * *} \\
(0.05)\end{array}$ & 1 & $\begin{array}{c}1.29 \\
(0.78)\end{array}$ & 1 & $\begin{array}{c}0.30^{* * *} \\
(0.09)\end{array}$ & 1 \\
\hline ingroup $\left(\beta_{2}\right)$ & $\begin{array}{c}0.14 \\
(0.17)\end{array}$ & 0.11 & $\begin{array}{c}0.58^{* * *} \\
(0.15)\end{array}$ & 2.60 & $\begin{array}{c}0.17 \\
(0.19)\end{array}$ & 0.13 & $\begin{array}{c}0.60^{* * *} \\
(0.15)\end{array}$ & 2.00 \\
\hline Egalitarian $\left(\beta_{3}\right)$ & $\begin{array}{l}- \\
-\end{array}$ & - & - & - & $\begin{array}{l}-0.38 \\
(0.30)\end{array}$ & -0.29 & $\begin{array}{c}0.22^{* * *} \\
(0.07)\end{array}$ & 0.73 \\
\hline Include No-tradeoff & & & $\mathrm{No}$ & & $\mathrm{N}$ & & $\mathrm{No}$ & \\
\hline Controls & & es & $\mathrm{Ye}$ & & $\mathrm{Ye}$ & & $\mathrm{Ye}$ & \\
\hline $\mathrm{N}$ & & 22 & 3,62 & & 3,6 & & 3,62 & \\
\hline Cases & & 7 & $90^{\prime}$ & & 90 & & $90^{\prime}$ & \\
\hline
\end{tabular}

Table 7: Conditional logit estimates. Standard errors, clustered at the subject level, in brackets below. *, **, $* * *$ indicate significance at the $10 \%, 5 \%$ and $1 \%$ level, respectively. Normalization: estimated equation times $\frac{1}{\beta_{1}}$.

\section{A.4 Additional Results: Post-Experimental Questionnaire}

\section{A.5 Time Trends}

Figure 15 - using the full sample - and Figure 16 - using "Best-In $<$ Best-Out" observations only - depict the average share of ingroup trades by treatment for each period. The data contain no strong, visible time trends for discrimination. This finding is confirmed by a regression of a dummy that indicates an ingroup trade in each of the treatments on the full set of period dummies. No period fixed effect in either of the two regressions (market vs non-market setting) turns out to be significant at the $5 \%$ level.

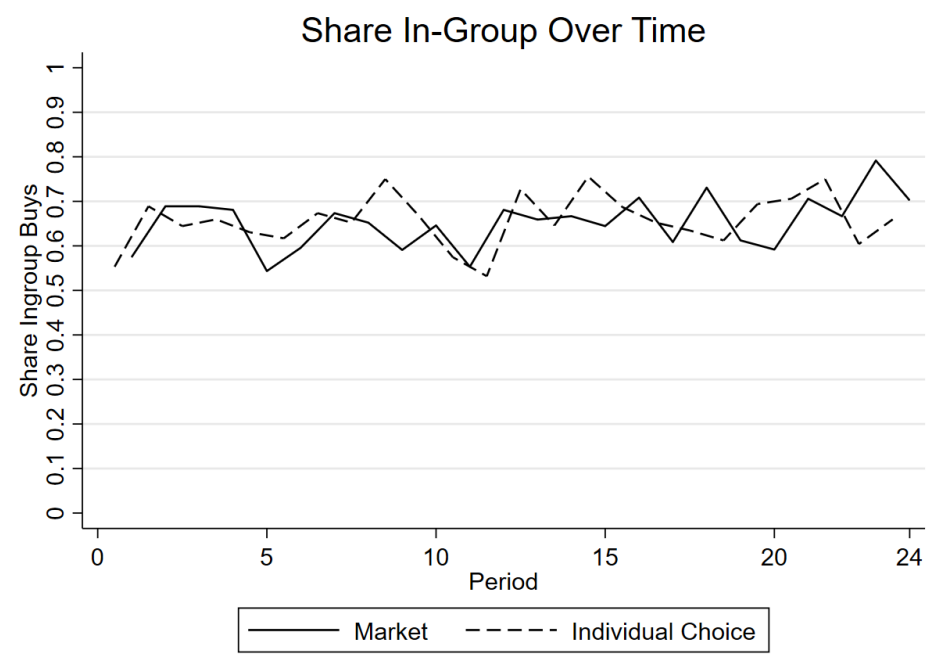

Figure 15: Share of ingroup buys by period, full sample $(N=1,133)$. 


\begin{tabular}{lccc}
\hline \hline & Market & Individual Choice & Rank Sum Test \\
\hline Identification & 0.21 & 0.43 & 0.055 \\
& {$[-0.002,0.42]$} & {$[0.21,0.65]$} & \\
Own Group Important & -1.21 & -0.48 & 0.000 \\
& {$[-1.42,-1.01]$} & {$[-0.69,-0.27]$} & \\
Support Member & -0.85 & -0.17 & 0.000 \\
Not Harming Member & {$[-1.07,-0.63]$} & {$[-0.35,0.02]$} & \\
& -0.63 & -0.12 & 0.001 \\
Own Payoff & {$[-0.85,-0.41]$} & {$[-0.29,0.06]$} & \\
& 0.86 & 0.14 & 0.000 \\
Altruist & {$[0.65,1.07]$} & {$[-0.05,0.33]$} & 0.000 \\
& -0.20 & 0.41 & \\
\hline \hline
\end{tabular}

Table 8: Answers to survey items by treatment. Higher values indicate more support. 95\% confidence intervals in brackets below. $N=121$. "Rank Sum Test" in the last column indicates p-values for null hypothesis that data are from the same population.

\section{A.6 Evolution of Market Prices}

Figure 17 shows the evolution of average payoffs by period. 


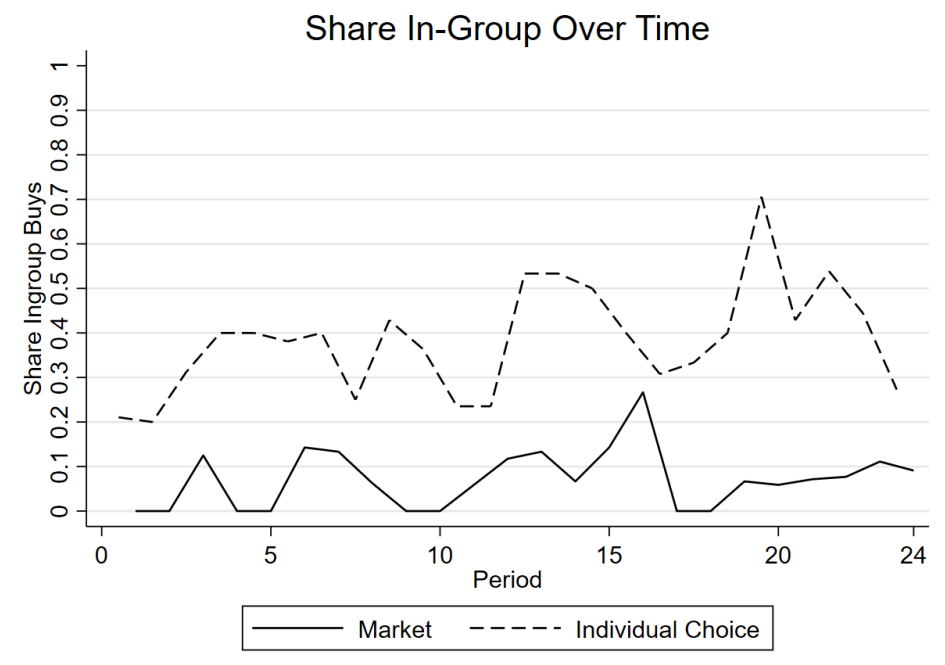

Figure 16: Share of ingroup buys by period, "Best-In < Best-Out" $(N=354)$.

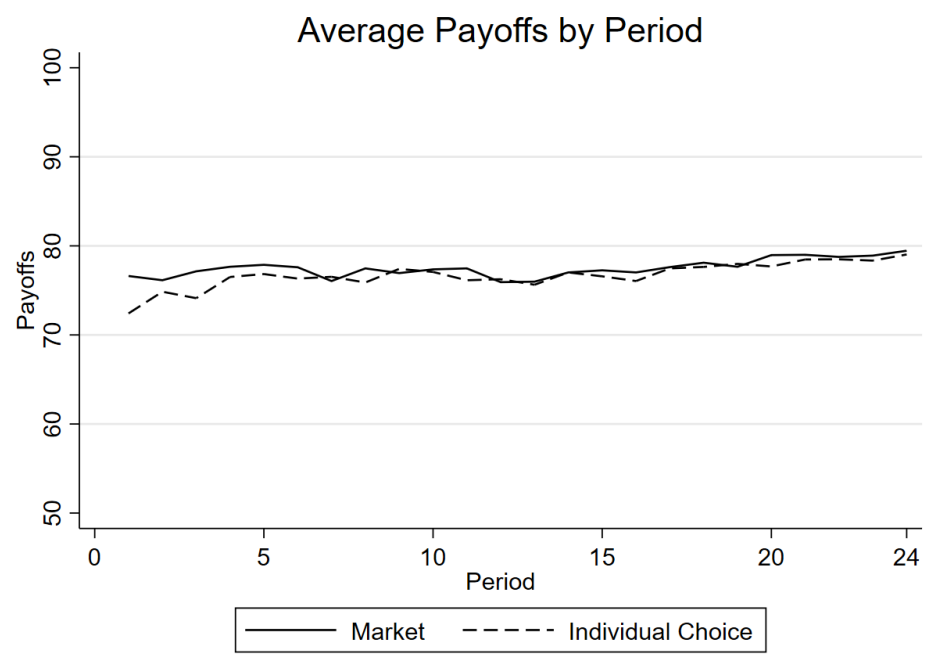

Figure 17: Evolution of payoffs to active participants over time. The price can be calculated as 100 minus the payoff. 


\section{A.7 Example: Relation of Market and Individual Choice Condition}

Figures 18 and 19 give an example of how the payoff-structure and the social group membership of passive players were transferred from the market treatment - Figure 18 - to the individual choice treatment - Figure 19. The payoffs for the active decision-maker and the passive subject are exactly the same in each row. For example, the offer in the third row in Figure 18 costs $p=2$ tokens and is made by a Kandinsky seller. The payoff functions for sellers and for buyers imply that the seller (the passive subject) would get a payoff of $P O_{\text {Seller }}=50+p=52$ and the buyer (the active subject) would get a payoff of $P O_{\text {Buyer }}=100-p=98$. The vector of payoffs and the information about the social group membership of the passive subject is then transferred to the individual choice treatment. The third row in Figure 19 displays the exact same payoff structure and identity information in the individual choice treatment. Each market decision screen is transferred in this way to the individual choice treatment in the exaxt same order as they appear in the market.

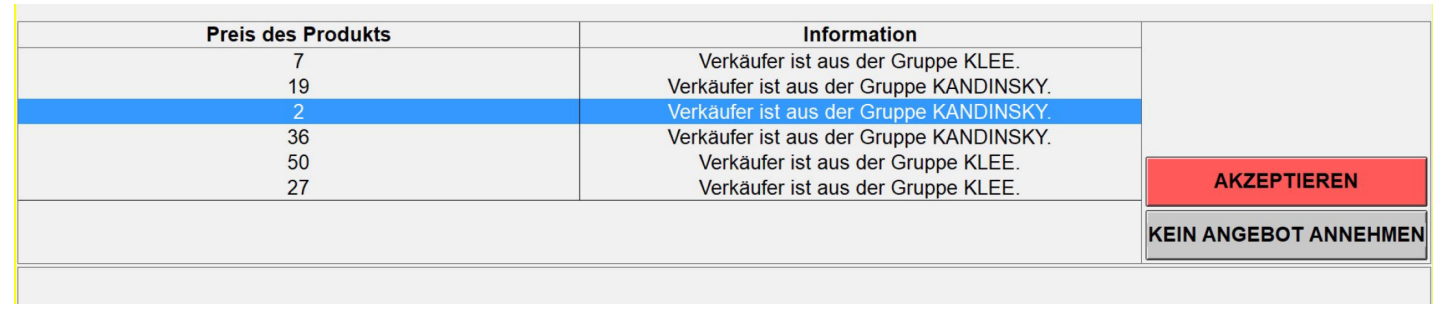

Figure 18: Market treatment. Selection of an offer by the buyer.

\begin{tabular}{|c|c|c|c|c|}
\hline Telinehmer A & Telinehmer B (Sie) & Information & Ihre Wahl: & \\
\hline 57 & 93 & $\begin{array}{l}\text { Teilnehmer ist aus der Gruppe } \\
\text { KLEE. }\end{array}$ & r & \\
\hline 69 & 81 & $\begin{array}{l}\text { Teilnehmer ist aus der Gruppe } \\
\text { KANDINSKY. }\end{array}$ & r & \\
\hline 52 & 98 & $\begin{array}{l}\text { Teilnehmer ist aus der Gruppe } \\
\text { KANDINSKY. }\end{array}$ & r & \\
\hline 86 & 64 & $\begin{array}{l}\text { Teilnehmer ist aus der Gruppe } \\
\text { KANDINSKY. }\end{array}$ & r & \\
\hline 100 & 50 & $\begin{array}{l}\text { Teilnehmer ist aus der Gruppe } \\
\text { KLEE. }\end{array}$ & $r$ & \\
\hline \multirow[b]{2}{*}{77} & \multirow[b]{2}{*}{73} & \multirow{2}{*}{$\begin{array}{l}\text { Teilnehmer ist aus der Gruppe } \\
\text { KLEE. }\end{array}$} & \multirow[b]{2}{*}{$r$} & USWÄHLEN \\
\hline & & & & KEINE NEUE VERTEILUNG AUSWĀHLEN \\
\hline
\end{tabular}

Figure 19: Individual choice treatment. Selection of a distribution by participant B.

\section{A.8 Translated Instructions}

\section{Part I: General Explanation}

Welcome to the experiment. If you read the instructions carefully and follow all the rules, you 
can earn money in this experiment. The money will then be paid out to you immediately in cash after the experiment is finished. You are not allowed to talk to other participants during any part of the experiment. If you have any questions, please address them exclusively to us. We will gladly answer your questions individually. Compliance with this rule is very important. If you fail to comply with these rules, the results of this experiment will be scientifically worthless.

This experiment consists of two parts, whereby each part is explained one after the other. The experiment is expected to last 90 minutes. In the following, the first part of the experiment is explained. Including the „show-up fee“for your punctual appearance, you can earn between 10 euros and 23 euros on both parts of the experiment.

\section{Detailed information on the first part of the experiment}

In the experiment you will see a series of ve screens. On each screen you will see two paintings side by side. One of the two paintings will always be by Wassily Kandinsky and the other by Paul Klee (you won't know which is which). Your role is to indicate on each screen which of the two paintings you like best. Simply let your taste guide you.

You will then be assigned to a group based on your decisions.

- If you like Kandinsky's paintings more often, you will be assigned to the KANDINSKY group.

- If you like Klee's pictures more often, you will be assigned to the KLEE group.

After you have been assigned to the KLEE or the KANDINSKY group, you will be asked to solve three joint tasks with the other members of your group. The tasks will be explained to you later in the experiment on the screens. When solving each task, you can chat with the other members of your group. Each member of your group can earn 1 euro per solved task. In total you can earn 3 euros in this first part of the experiment. In both parts of the experiment, we will not be talking about euros but about points. Your total income is therefore first calculated in points. The points you earn during the first part will then be converted to euros at the end, using the following conversion rate:

$$
5 \text { points }=1 \text { euro. }
$$

After the first part of the experiment has been completed, the rules for the second part of the experiment will be distributed and read aloud.

If you still have questions, please raise your hand and wait quietly until someone comes to you.

\section{Part II: INDIVIDUAL CHOICE CONDITION}


This second part of the experiment involves two types of participants: Participants A and B. The participants in this experiment are divided into groups of 11 persons each. In each society there are six Participants A and five Participants B. At the beginning of the second part of the experiment you will learn whether you are a Participant A or a Participant B. In the second part of the experiment you will also still be a member of the KLEE or the KANDINSKY group. Just like your assignment to the KLEE or KANDINSKY group, you will remain a Participant A or a Participant B throughout the experiment. Participant A and Participant B thus come from the KLEE or KANDINSKY groups.

In this second part of the experiment, we will not be talking about euros but about points. Your total income will be calculated in points. The points you earn in the second part of the experiment will be converted to euros at the end, using the following exchange rate:

\section{Points $=2$ euros.}

The second part of the experiment will run over 24 periods. In each period a Participant B can select a particular distribution of points between himself and Participant A from a list of distributions. The distributions differ according to the distribution of points between Participant B and Participant A and also between the group to which Participant A belongs. Participant A can therefore be a member of the KLEE or the KANDINSKY group. This information is displayed for each person for each distribution. The system displays the group (KLEE or KANDINSKY) from which Participant A comes to Participant B. It is also important to note that the list of distributions between the periods can vary in length. The list always contains two to six distributions, of which only one distribution can be selected at a time.

Each participant's payo will be calculated as follows. In each period, each Participant A and Participant B receives an endowment of 50 points. Each of the distributions available for selection assigns at least these 50 points to Participants A and B. The allocation of 50 points to Partici- pants A and B is made as follows A total of 150 points is distributed between Participant $\mathrm{A}$ and Participant $\mathrm{B}$ for each distribution.

If a Participant $\mathrm{B}$ now chooses a certain distribution, he directly assigns himself a certain number of points, which determines his payoff in the corresponding period. At the same time, a Participant A from either the KLEE or the KANDINSKY group is assigned to each distribution. Depending on whether Participant B decides for a distribution according to which Participant A from the KLEE or the KANDINSKY group is assigned a number of points, Participant B will determine the payoff for the participant assigned to the distribution. The payoff to the remaining Participant A is then determined either by another Participant B or amounts to 50 points. It is also possible that

Participants A in the list of distributions come exclusively from either the KLEE group or the KANDINSKY group. Since the five Participants B have selected a maximum of five distributions by the end of each period, in each period at least one Participant A will receive 
only his 50 points from the initial endowment.

\section{The course of a period on the computer:}

In each period, Participant B can see the new distributions on the following screen:

\section{Example Screen 1:}

\begin{tabular}{|c|l|l|}
\hline Teilnehmer A & Teilnehmer B (Sie) & Information \\
\hline 57 & 93 & $\begin{array}{l}\text { Teilnehmer ist aus der Gruppe } \\
\text { KLEE. }\end{array}$ \\
\hline 69 & 81 & $\begin{array}{l}\text { Teilnehmer ist aus der Gruppe } \\
\text { KANDINSKY. }\end{array}$ \\
\hline 52 & 98 & $\begin{array}{l}\text { Teilnehmer ist aus der Gruppe } \\
\text { KANDINSKY. }\end{array}$ \\
\hline 86 & 64 & $\begin{array}{l}\text { Teilnehmer ist aus der Gruppe } \\
\text { KANDINSKY. }\end{array}$ \\
\hline 100 & 50 & $\begin{array}{l}\text { Teilnehmer ist aus der Gruppe } \\
\text { KLEE. }\end{array}$ \\
\hline 77 & 73 & $\begin{array}{l}\text { Teilnehmer ist aus der Gruppe } \\
\text { KLEE. }\end{array}$ \\
\hline
\end{tabular}

The left column of the table shows the points assigned to Participant A for each corresponding distribution. Column 2 shows the points assigned to Participant B (i.e. the decision-maker). The third column indicates for each distribution whether Participant A assigned to the distribution comes from the KLEE or the KANDINSKY group. In the last column on the far right, a preselection can be made by ticking the box.

Participant B can select one of the distributions of points between Participant A and Participant B. He or she cannot choose a distribution. In this case, he or she and one of the assigned Participants A (either a KLEE or a KANDINSKY) would be assigned the initial endowment of 50 points as a payoff. If Participant $\mathrm{B}$ does not want to select a distribution, he must press the SELECT NO NEW DISTRIBUTION button. When Participant B has made a final distribution decision, the distribution can be selected by ticking the last column and clicking the red SELECT button.

Participant A cannot make a decision in this experiment. However, we ask Participants A to indicate in each period how they expect the Participants B to behave.

When all participants have been informed of their payoffs, the next period begins. Your final payoff from this second part of the experiment is the payoff from a randomly selected period. Since you do not know which period the computer randomly selects, you should consider your decision carefully in each of the 24 periods. At the end of the experiment, the corresponding number of points is converted to euros (10 points $=2$ euros $)$ and paid to you in cash together with the payment from the first part of the experiment. Altogether you can earn up to 23 euros in this experiment, namely up to 3 euros in the first part and up to 20 euros in the second part. 


\section{If you still have questions, please raise your hand high in your booth and wait quietly until someone comes to you. If you have no further questions, the second part of the experiment will start.}

\section{Part II: MARKET}

In this second part of the experiment, two types of participants meet in a market: seller and buyer. The participants in this experiment are divided into groups of 11 persons each. Each group consists of six sellers and five buyers meeting in a market. At the beginning of the experiment, your computer screen will tell you whether you are a seller or a buyer. In the second part of the experiment you remain a member of the KLEE or the KANDINSKY group just like in the first part of the experiment. The same as your assignment to the KLEE or the KANDINSKY group, your role as a seller or buyer will remain the same throughout the whole experiment.

In the second part of the experiment, we will not be talking about euros but about points. Your total income will therefore be first calculated in points. The points you earn during the second part of the experiment are converted into euros at the end, using the following exchange rate:

\section{Points $=2$ euros}

The second part of the experiment runs over 24 periods, with each period representing a market. In each period, each seller makes exactly one sales offer for only one product. A seller then sets the price for the product. The price can be anywhere between 0 and 50 points. The production cost of the seller for a product is 0 points. The value of a product for a buyer is always 50 points, regardless of the type of product.

The five buyers see the offers to sell made by the six sellers (i.e. the price) and each of them can accept one offer. The buyers decide in random order one after another. Each buyer can only accept one offer. In each period a maximum of five of the six sellers can sell a product. The sellers are in competition with other sellers, because the buyers can freely choose whether they (i) buy a product at all and (ii) which product they buy. The buyers (but not the sellers) are shown the selling price and the group (KLEE or KANDINSKY) from which the seller comes.

In each period, each seller and buyer initially receives 50 points. The payoffs to the seller and the buyer (in points) in a period are thus as follows:

\section{Profits from sellers in a market:}

- If the offer to sell is accepted by one of the buyers:

50 - production costs + price of the product

- If the offer to sell is not accepted by a buyer in a given period: 


\section{Profits from buyers in every market:}

- If the offer to sell is accepted:

$50+50-$ price of the product

- If the offer to sell is not accepted:

50

The process of a market on the computer:

Each period consists of exactly one market. The sellers enter their sales offer in the experiment as on Example screen 1:

Example screen 1: (Enter sales price 0-50)

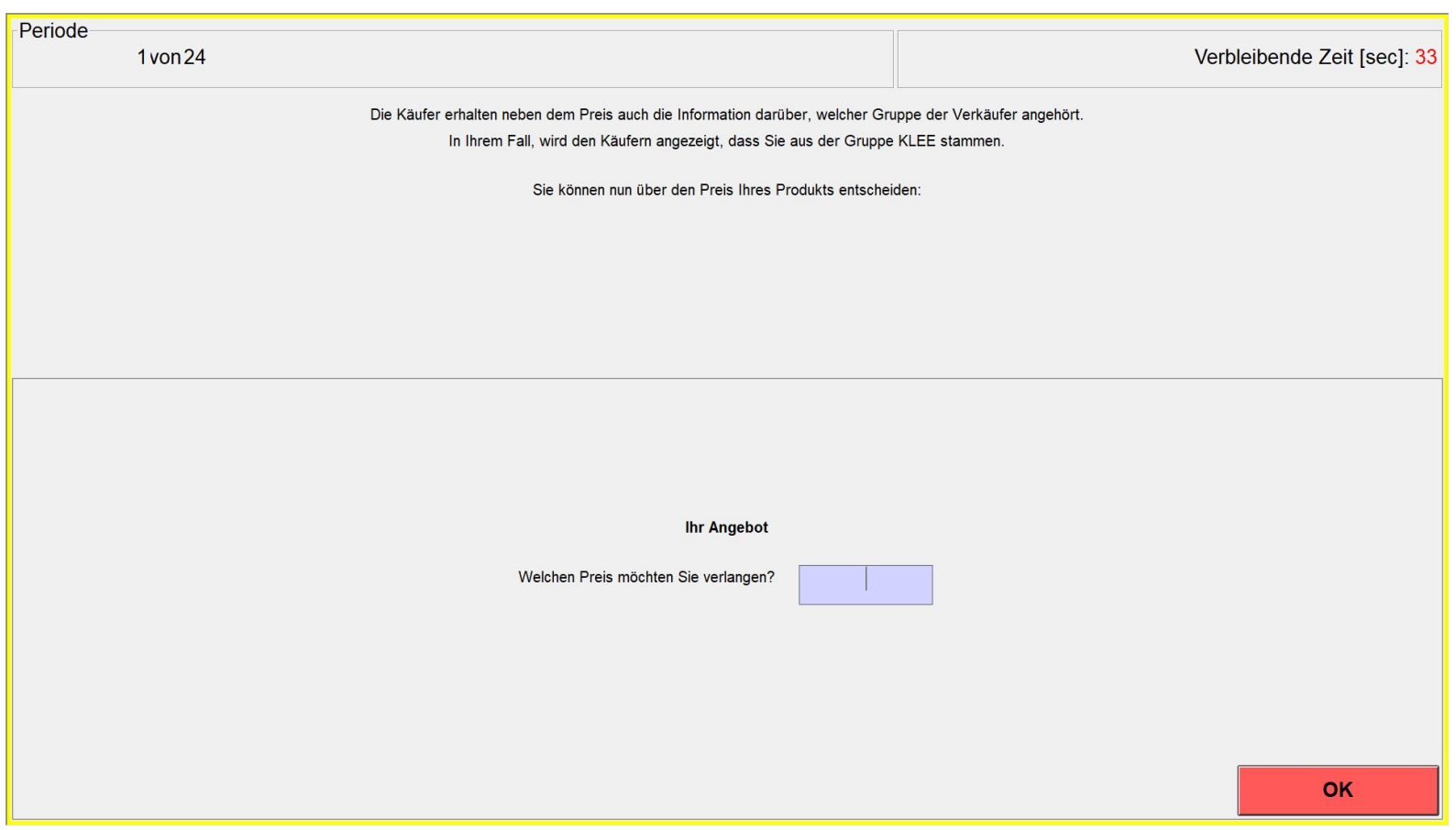

Figure 20

A seller must indicate the price he wishes to charge for the product. To do this, enter the appropriate number in the field. The price can be any integer from 0 to 50 inclusive. When a seller has made his decisions, the OK button in the bottom right corner must be pressed.

Once all six sellers have made their sales offers, the sellers see the offers (prices) made by all the other sellers in a table. Example screen 2 shows this overview.

\section{Example screen 2: (Display of the acceptance of offers for the sellers)}

Your own sales offer is always marked in blue. In the column on the far right, the sellers can follow whether and in which order the offers are accepted by the buyers. Once all the buyers have made their decisions, each seller receives his own payoff and - if his offer to sell was accepted - the payoff of the buyer who accepted the offer. In each period the buyers can accept the offers 


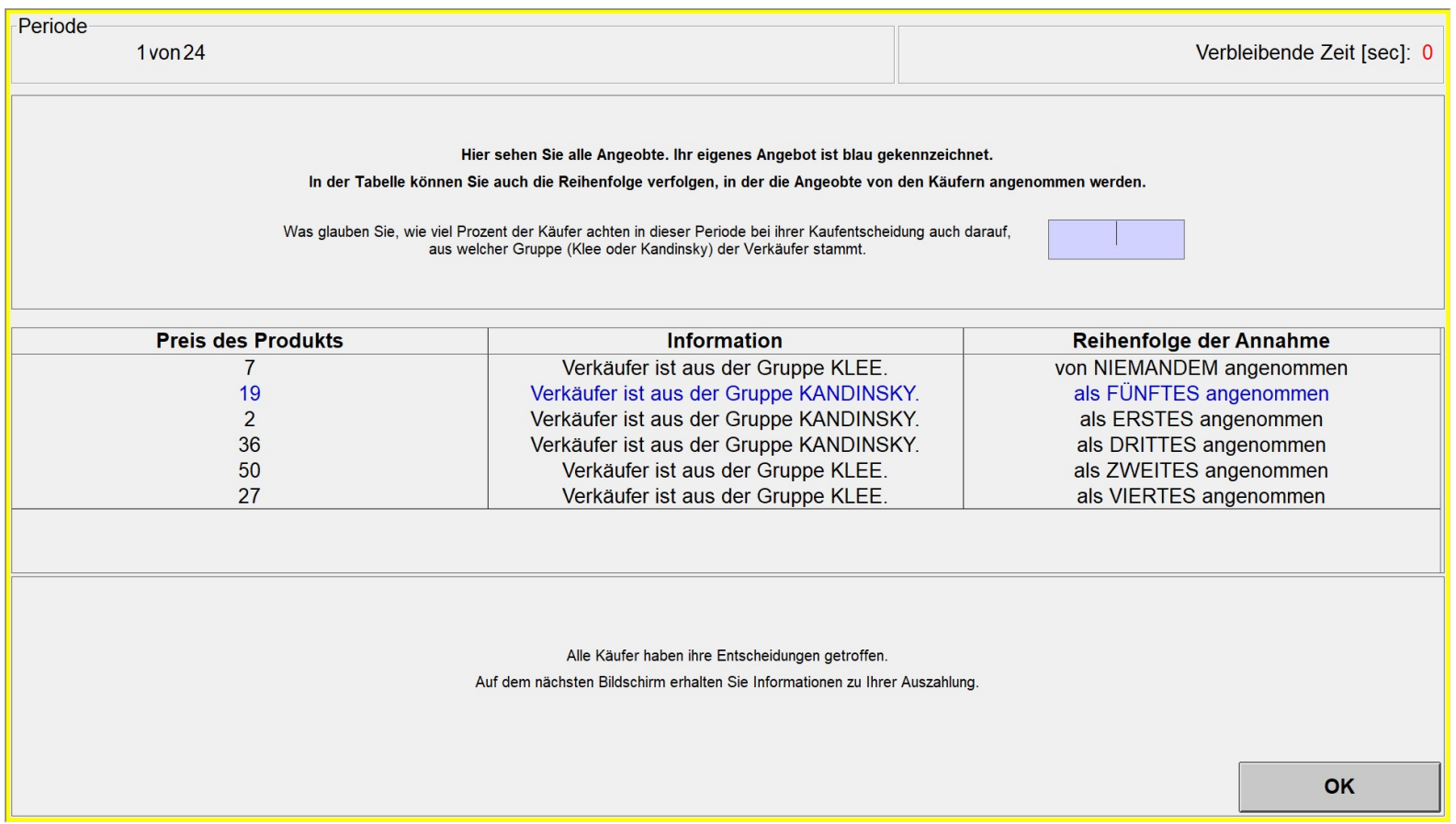

Figure 21

for sale. This situation is illustrated in Example screen 3: Example screen 3: (Selection of an offer by the buyer)

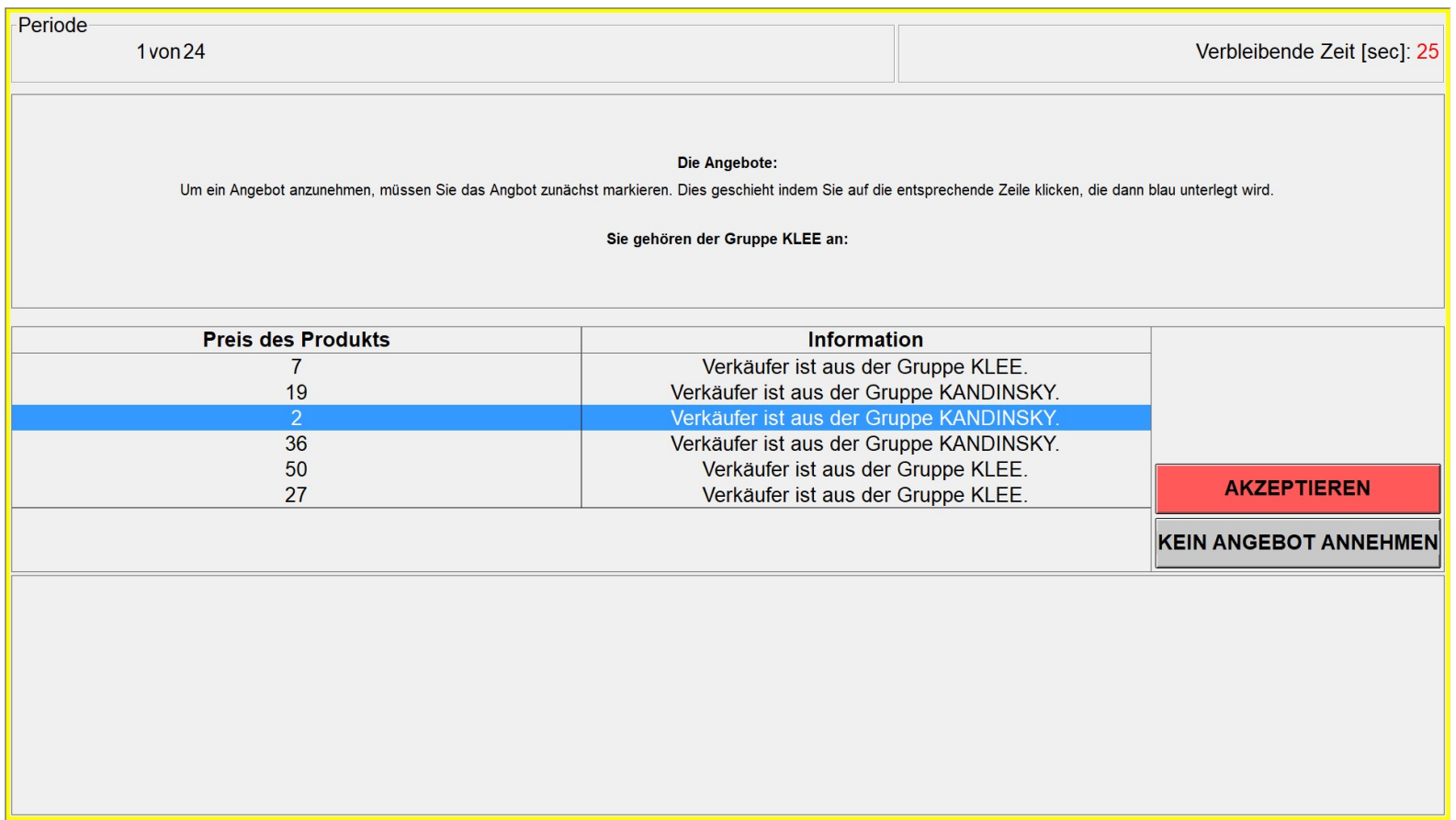

Figure 22

The buyers see the above screen in random order and can accept one offer after the other. 
At any time only one buyer can see the above screen. Only when the current buyer has made his decision does the next buyer see this screen, on which he can then accept an offer. The buyer to whom the screen is displayed first can therefore choose from all the offers. The buyer to whom the screen is displayed second can select only from the remaining offers, since each offer can only be accepted by one buyer. If the five buyers each accept an offer, there is always one offer left that can no longer be accepted. The seller who made this offer will not be able to conclude a deal in this period. The order in which the five buyers can decide to accept the six offers is determined randomly in each period.

The left-hand column of the table shows the prices, the middle column shows the seller's group affiliation (KANDINSKY or KLEE). Every line displays one offer at a time. To accept an offer, first click on that line with the mouse. The marked line is then highlighted in blue.

Before you press the ACCEPT button, you can still change your offer selection.

If a buyer does not want to accept an offer, the ACCEPT NO OFFER button must be pressed. Even if a line has already been selected, you can still reject all offers with the ACCEPT NO OFFER button. Once all buyers have made their decisions in this market, each buyer notes his own profit.

When all the participants have been informed of their profits in the market, the next market begins. Your profit from this second part of the experiment is the payoff from a randomly selected market. Since you do not know which market was randomly selected by the computer, you should consider your decision carefully in each of the 24 markets. At the end of the experiment, the corresponding number of points will be converted to euros (10 points $=2$ euros) and paid out to you in cash together with the payoff from the first part of the experiment. In total you can earn up to 23 euros in this experiment, namely up to 3 euros in the first part and up to 20 euros in the second part.

If you still have questions, please raise your hand high in your booth and wait quietly until someone comes to you. If you have no further questions, the second part of the experiment will start. 


\section{A.9 Sample Screens Online Survey}

\section{Teil 2 - Kaufentscheidung 1/24}

Sie sind für die gesamte Dauer der Studie ein Käufer und gehören der Gruppe der Kölner an.

Bitte wählen Sie nun ein Angebot aus. Bedenken Sie hierbei: Je niedriger der Preis des ausgewählten Angebotes, desto höher ist lhre Auszahlung. Bedenken Sie auch, dass Sie durch lhre Kaufentscheidung und die damit verbundene Preisauswahl lhre eigene Auszahlung und auch die Auszahlung der Verkäufer festlegen.

\begin{tabular}{|c|c|c|}
\hline Ihre Wahl & Preis & \multicolumn{1}{|c|}{ Information } \\
\hline 0 & $\mathbf{1 4}$ & Verkäufer ist aus der Gruppe KÖLN \\
\hline & $\mathbf{4 0}$ & Verkäufer ist aus der Gruppe Berlin \\
\hline
\end{tabular}

Figure 23: Market treatment. Selection of an offer by the buyer.

\section{Teil 2 - Verteilungsentscheidung 1/24}

Sie sind für die gesamte Dauer der Studie ein Teilnehmer B und gehören der Gruppe der KöLNER an.

Bitte wählen Sie nun eine Verteilung aus. Bedenken Sie hierbei, dass Sie durch Ihre Entscheidung lhre eigene Auszahlung und auch die Auszahlung der Teilnehmer A festlegen.

\begin{tabular}{|c|c|c|c|c|}
\hline Ihre Wahl: & Information & & Teilnehmer A & Teilnehmer B (Sie) \\
\hline $\mathrm{O}$ & Teilnehmer A ist aus der Gruppe KÖLN & 붑ㅂㅂ & 58 & 92 \\
\hline 0 & Teilnehmer A ist aus der Gruppe BERLIN & 7 & 70 & 80 \\
\hline
\end{tabular}

Figure 24: Individual choice treatment. Selection of a distribution by participant B. 